OPEN ACCESS

Edited by:

Chetan Seshadri,

University of Washington,

United States

Reviewed by:

Reinout Van Crevel,

Radboud University Nijmegen Medical

Centre, Netherlands

Carmen Judith Serrano,

Mexican Social Security Institute

(IMSS), Mexico

*Correspondence:

Jesús Gutierrez

jesus.gutierrez@case.edu

${ }^{\dagger}$ These authors have contributed equally to this work

Specialty section: This article was submitted to Microbial Immunology, a section of the journal

Frontiers in Immunology

Received: 21 October 2020 Accepted: 14 January 2021 Published: 25 February 2021

Citation:

Gutierrez J, Kroon EE, Möller M and Stein CM (2021) Phenotype Definition

for "Resisters" to Mycobacterium tuberculosis Infection in the Literature -A Review and Recommendations.

Front. Immunol. 12:619988. doi: 10.3389/fimmu.2021.619988

\section{Phenotype Definition for "Resisters" to Mycobacterium tuberculosis Infection in the Literature-A Review and Recommendations}

\author{
Jesús Gutierrez ${ }^{1 \star \dagger}$, Elouise E. Kroon ${ }^{2 \dagger}{ }^{\text {, Marlo Möller }}{ }^{2}$ and Catherine M. Stein ${ }^{1}$ \\ ${ }^{1}$ Department of Population and Quantitative Health Science, Case Western Reserve University School of Medicine, \\ Cleveland, OH, United States, 2 DSI-NRF Centre of Excellence for Biomedical Tuberculosis Research, South African Medical \\ Research Council Centre for Tuberculosis Research, Division of Molecular Biology and Human Genetics, Faculty of Medicine \\ and Health Sciences, Stellenbosch University, Cape Town, South Africa
}

Tuberculosis (TB) remains a worldwide problem. Despite the high disease rate, not all who are infected with Mycobacterium Tuberculosis (Mtb) develop disease. Interferon- $\gamma$ (IFN- $\gamma$ ) specific T cell immune assays such as Quantiferon and Elispot, as well as a skin hypersensitivity test, known as a tuberculin skin test, are widely used to infer infection. These assays measure immune conversion in response to Mtb. Some individuals measure persistently negative to immune conversion, despite high and prolonged exposure to $\mathrm{Mtb}$. Increasing interest into this phenotype has led to multiple publications describing various aspects of these responses. However, there is a lack of a unified "resister" definition. A universal definition will improve cross study data comparisons and assist with future study design and planning. We review the current literature describing this phenotype and make recommendations for future studies.

Keywords: tuberculosis, resister, phenotype, tuberculin skin test, interferon- $\gamma$ release assay, review

\section{INTRODUCTION}

Tuberculosis (TB) remains a major public health problem globally. Since 2007, Mycobacterium tuberculosis $(\mathrm{Mtb})$ has been responsible for the greatest number of deaths from a single infectious agent around the world. In 2018, 10.0 million people developed active disease and approximately 1.5 million people died (1). One of the challenges faced in developing effective TB preventative treatment strategies is understanding the underlying innate and adaptive responses to natural clearance of $M t b$. We currently lack a gold standard to measure infection and can only infer it from a tuberculin skin test (TST) or in vitro based Interferon- $\gamma$ (IFN- $\gamma$ ) release assays (IGRA). These assays are markers of immune conversion in response to $M t b$ exposure and do not capture the full spectrum of anti- $M t b$ immunity (2-4). Despite this inherent limitation, the study of persons who test persistently negative for these assays and do not develop TB provide unique and important epidemiological, genetic, and immunological insights into understanding the possible mechanisms of infection clearance $(2,5)$.

There are several historical case contact studies that point to the existence of a group of individuals who remain negative for reactivity to a TST despite heavy and repeated exposure to $M t b$ 
$(2,5,6)$. These individuals have been previously labeled as "resisters" or "early clearers" of infection. For example, two different studies described the cumulative prevalence of these individuals among nurses and nursing students (7-9). One study took place at the Boston City Hospital from 1932 to 1947 and revealed that 52 out of 362 nurses (14.4\%) fit this phenotype over a three-year follow-up period (7). The other study was performed at Fairview Hospital in Minneapolis and found that 16 out of 184 nursing students (8.7\%) did not show any evidence of reactivity to a TST during a three-year follow-up (8). Another study performed in 1966 aboard the U.S.S. Richard E. Byrd found that $7 \mathrm{crew}$ members out of approximately 70 who shared the same berthing compartment as a symptomatic pulmonary TB sailor remained TST negative during a 6-month follow-up (10). As one of these studies points out, these individuals appeared to be "endowed with a very superior resistance to tuberculosis which destroyed the tubercle bacillus before it could establish a 'beach head' in the body" (7).

Although recent work suggests this phenotype may be best characterized immunologically (4), several longitudinal epidemiological studies have attempted to define this "resister" phenotype using IGRAs in addition to the TST. Unfortunately, due to the heterogeneity of these studies as well as the instability observed in TST and IGRA results, a unifying definition has been difficult to ascertain.

Perhaps the greatest obstacle in trying to define a unified phenotype of resistance to TB is the inability to define a singular state. Resistance to $M t b$ remains a spectrum and is dependent on host, environmental and bacterial factors. To date, both household contact studies as well as community studies have been used to facilitate the identification of the spectrum of phenotypes of interest and these studies include cross sectional, case-control, and cohort study designs.

The purpose of this review is to, according to study design, summarize how different studies in the literature describe individuals who test IGRA and TST negative after single or multiple $M t b$ exposure (Tables 1 and 2). Second, we compare the differences. Third, based on the differences, we argue why a single definition of a "resister" phenotype may be inadequate. Lastly, we aim to make recommendations on how future studies should approach their study design and definitions.

\section{STUDY DESIGNS AND DEFINITIONS}

\section{Household Contact Studies}

The past few years has seen increased interest in using household contact studies in order to understand the pathophysiology of $M t b$ infection-including the host immune response-and to define "resistance" or "early clearance" to infection. Some of the advantages of this particular study design include the ability to recruit a highly exposed group of individuals who can be followed prospectively while collecting extensive epidemiological data (11). All of these aspects ensure that all stages of $M t b$ infection and disease can be captured allowing a more defined and robust phenotypic examination (11).

\section{Kampala, Uganda}

The study by Stein et al. is unique among household contact (HHC) studies in that it revisited a cohort that had been originally recruited between 2002 and 2012 in order to assess the robustness of the "resister" phenotype several years later (12). This follow-up study retraced $407 \mathrm{HIV}$ negative participants who were at least 15 years of age at the start of the retracing study and who had been initially classified as "persistent TST negative" (negative TST results for a minimum of 12 months and up to 24 months optimally) or "TST negative incomplete" (negative TST results for less than 12 months). The average time in between recruitment for these studies was approximately 9.5 years (12).

In addition to the TST used in the previous study, Stein et al. added the use of the QuantiFERON TB Gold In-Tube (QFT) test to further refine the "resister" phenotype. There were three QFT tests performed per participant. The first one was done at baseline followed by two others done in the 1 to 2 -year period after baseline. A final TST (5 tuberculin units [TU], PPD-S2, Tubersol, Sanofi Pasteur Limited, USA) was performed following the last QFT test. Based on the additional testing, participants were further grouped into the following "resister" categories: "definite resister", "probable resister", and "possible resister" (see Table 1). The investigators defined certainty level using quantitative values of the QFT and TST such that if values were close to the positive/negative thresholds, they had a lower level of certainty. The levels of certainty also incorporated missed visits for both IGRA and TST data. Stein et al. also highlighted the presence of 32 TST/QFT "discordant" individuals who had consistent TST results but opposite QFT tests results. At the end of the study, most (82.7\%) of the retraced "persistent TST negatives" remained QFT and repeat TST negative ("resisters") while $16.3 \%$ converted to LTBI and $1.0 \%$ were labelled as "discordant". In addition, $91.7 \%$ of these "resisters" had a TST of $0 \mathrm{~mm}(12)$.

\section{Chennai and Pune, India}

Mave et al. recruited a total of 799 children, adolescents and adults who had been living in the same household of an adult pulmonary TB index case from two different sites in India (15). Follow-up included three QFT tests and three TSTs (5 TU, PPD, SPAN/Arkray, India) at baseline, at 4 months and at 12 months. The cut offs used for the QFT tests were those suggested by the manufacturer and they used the more stringent $5 \mathrm{~mm}$. cut off for the TST on all subjects. They also classified HHCs using a TB risk score and defined high exposure as those adults with a score $>6$ and children with a score $>5(13,14)$. Using these tests, the authors defined the following phenotypes: "persistent LTBI negative" (pLTBI-), "resisters", and "resisters with a complete absence of response" (Table 1). By the end of the follow up period, $91.6 \%$ of all HHCs developed latent TB infection. Sixtyseven HHCs (8\%) were classified as "pLTBI-" and 52 of these were further classified as "resisters". Although none of these "resisters" had a complete absence of response to both tests, approximately half of them had no response to at least one of the tests. Finally, the authors mentioned that the two tests only had a $60 \%$ agreement but did not reveal how they dealt with discordant results. 
TABLE 1 | Summary of tests and definitions used by household contact studies.

\begin{tabular}{|c|c|c|c|c|c|c|c|}
\hline $\begin{array}{l}\text { Household } \\
\text { contact study }\end{array}$ & Study location & Risk score used & Tests used & Cut-offs & Resister' definition & Other definitions & LTBI definition \\
\hline $\begin{array}{l}\text { Stein et al. (11, } \\
12)\end{array}$ & Kampala, Uganda & $\begin{array}{l}\text { Validated TB risk score by } \\
\text { Mandalakas et al. (13); Ma et al. } \\
\text { (14) }\end{array}$ & $\begin{array}{l}\text { TST (5 tuberculin units } \\
\text { [TU], PPD-S2, Tubersol, } \\
\text { Sanofi Pasteur Limited, } \\
\text { USA) } \\
\text { QFT Gold In-Tube (QFT- } \\
\text { GIT) }\end{array}$ & $\begin{array}{l}\text { TST: } 10 \mathrm{~mm} \text { (HIV- contacts) and } \\
5 \mathrm{~mm} \text { (HIV+ contacts) } \\
\text { QFT: IFN- } \gamma \text { (TB Ag - Nil) at } 0.35 \\
\text { IU/ml }\end{array}$ & $\begin{array}{l}\text { Initial houlsehold contact study: } \\
\text { TST negative after at least } 12 \\
\text { months of follow-up. Retracing } \\
\text { study: Three negative QF tests } \\
\text { (one at baseline and two others } \\
\text { during the } 1-2 \text { year follow-up } \\
\text { period) and a final negative TST } \\
\text { following the last QFT test. } \\
\text { Average duration of time in } \\
\text { between studies: } 9.5 \text { years. }\end{array}$ & $\begin{array}{l}\text { Probable 'resister': one 'low } \\
\text { level positive' QFT that disagreed } \\
\text { with the other } 4 \text { data points. A low } \\
\text { level positive included values of } \\
0.35 \mathrm{IU} / \mathrm{ml} \text { < IFN- } \gamma \text { (TB Ag - Nil) < } \\
0.5 \mathrm{IU} / \mathrm{ml} \text {. } \\
\text { Possible 'resister': TST } \\
\text { induration } \leq 8 \mathrm{~mm} \text { or one QFT } \\
\text { positive plus all other negative } \\
\text { tests or a TST negative incomplete } \\
\text { with } 2 \text { negative QFTs but missing } \\
\text { the last visit of the study. }\end{array}$ & $\begin{array}{l}\text { Definite LTBI: All TST and QFT + } \\
\text { Definite converters: Persistently } \\
\text { TST negative in initial study who } \\
\text { converted to } 3+\text { QFT and a +TST } \\
\text { on retracing. }\end{array}$ \\
\hline $\begin{array}{l}\text { Mave et al. } \\
\text { (15) }\end{array}$ & $\begin{array}{l}\text { Chennai and Pune, } \\
\text { India }\end{array}$ & $\begin{array}{l}\text { Validated TB risk score by } \\
\text { Mandalakas et al. (13); Ma et al. } \\
\text { (14) }\end{array}$ & $\begin{array}{l}\text { TST (5 TU, PPD, SPAN/ } \\
\text { Arkray, India) } \\
\text { QFT-GIT }\end{array}$ & $\begin{array}{l}\text { TST: } 5 \mathrm{~mm} \\
\text { QFT: IFN- } \gamma \text { (TB Ag - Nil) at } 0.35 \\
\text { IU/ml }\end{array}$ & $\begin{array}{l}\text { HHCs with high TB exposure who } \\
\text { were TST and QFT negative at } \\
\text { baseline and up to } 12 \text { months } \\
\text { following exposure (TST < } 5 \mathrm{~mm} \\
\text { and QFT IFN- } \gamma \text { (TB Ag }- \text { Nil) < } \\
0.35 \mathrm{IU} / \mathrm{mL} \text { ). }\end{array}$ & $\begin{array}{l}\text { Persistent LTBI negative } \\
\text { (pLTIB-): TST and QFT negative } \\
\text { at baseline and up to } 12 \text { months } \\
\text { following exposure. } \\
\text { 'Resisters' with complete } \\
\text { absence of response: TST = } \\
\text { Omm and IFN- } \gamma \text { (TB Ag - Nil) < } \\
0.01 \mathrm{IU} / \mathrm{ml} \text {. }\end{array}$ & $\begin{array}{l}\text { LTBI: At least one positive TST or } \\
\text { QFT test. TST } \geq 5 \mathrm{~mm} \text { or QT IFT- IFN- } \\
\gamma(\text { TB Ag }- \text { Nil) } \geq 0.35 \mathrm{IU} / \mathrm{mL} \text {. }\end{array}$ \\
\hline $\begin{array}{l}\text { Verrall et al. } \\
(16,17)\end{array}$ & $\begin{array}{l}\text { Bandung, } \\
\text { Indonesia }\end{array}$ & $\begin{array}{l}\text { Score, derived using regression } \\
\text { methods, was based on the index } \\
\text { TB case's sputum smear grade, } \\
\text { the presence of cavities and the } \\
\text { extent of the CXR disease }\end{array}$ & QFT- GIT & IFN- $\gamma($ TB Ag - Nil) at $0.35 \mathrm{IU} / \mathrm{ml}$ & $\begin{array}{l}\text { Persistently negative (Early } \\
\text { clearers): Persistently IFN- } \gamma \text { (TB } \\
\text { Ag - Nil) }<0.35 \mathrm{IU} / \mathrm{ml} \text { at baseline } \\
\text { and at } 14 \text { weeks. }\end{array}$ & & $\begin{array}{l}\text { Conversion: IFN- } \gamma \text { (TB Ag }- \text { Nil) }< \\
0.35 \mathrm{IU} / \mathrm{ml} \text { at baseline to IFN- } \gamma \text { (TB } \\
\text { Ag }-\mathrm{Nil})>0.35 \mathrm{IU} / \mathrm{ml} \text { at } 14 \\
\text { weeks. }\end{array}$ \\
\hline Hill et al. (18) & $\begin{array}{l}\text { Banjul, The } \\
\text { Gambia }\end{array}$ & No risk score used & $\begin{array}{l}\text { TST (2 TU, PPD RT23, } \\
\text { Statens Serum Institut, } \\
\text { Denmark) } \\
\text { ELISPOT }\end{array}$ & $\begin{array}{l}\text { TST: } 10 \mathrm{~mm} \\
\text { ELISPOT: For a positive ESAT-6/ } \\
\text { CFP-10 result it was necessary for } \\
\text { at least one of the two pools of } \\
\text { overlapping peptides to be } \\
\text { positive. Phytohaemagglutinin } \\
\text { wells were set to at least } 150 \text { SFU/ } \\
\text { well/2 } 2 \times 10 \wedge 5 \text { above negative } \\
\text { control wells. Negative control } \\
\text { wells were required to have less } \\
\text { than } 20 \text { SFU. }\end{array}$ & $\begin{array}{l}\text { HHCs with high TB exposure: TST } \\
<\text { < } 5 \mathrm{~mm} \text { at baseline and } 18 \text { months } \\
\text { following exposure and negative } \\
\text { ELISPOT at baseline, } 3 \text { months } \\
\text { and } 18 \text { months following } \\
\text { exposure. }\end{array}$ & & $\begin{array}{l}\text { TST conversion: Negative at } \\
\text { baseline and } \geq 10 \mathrm{~mm} \& \text { an } \\
\text { increase in induration } \geq 6 \mathrm{~mm} \text { at } \\
18 \text { months. } \\
\text { Positive ELISPOT: ESAT- } 6 / \text { CFP- } \\
10-\text { a t least one of the two pools } \\
\text { of overlapping peptides positive. } \\
\text { ELISPOT conversion: as a newly } \\
\text { positive test, plus a change in the } \\
\text { combined ESAT-6 and CFP-10 } \\
\text { count ( }>\text { negative control) } \geq 6 \\
\text { SFU/well/2x10^5 ( } 30 \mathrm{SFU} / \mathrm{million} \\
\text { cells). }\end{array}$ \\
\hline $\begin{array}{l}\text { Coulter et al. } \\
\text { (19) }\end{array}$ & The Gambia & $\begin{array}{l}\text { Based on sleeping proximity to the } \\
\text { index TB case and smear grade of } \\
\text { the index TB case }\end{array}$ & in-house IGRA & Unknown & $\begin{array}{l}\text { Non-converters: IGRA negative } \\
\text { at baseline and at } 6 \text { months }\end{array}$ & & $\begin{array}{l}\text { LTBI: IGRA positive at baseline } \\
\text { IGRA converters: IGRA negative } \\
\text { at baseline and IGRA positive at } 6 \\
\text { months }\end{array}$ \\
\hline $\begin{array}{l}\text { Medawar et al. } \\
\text { (20) }\end{array}$ & The Gambia & $\begin{array}{l}\text { HHCs sleeping in the same room } \\
\text { as index TB case }\end{array}$ & QFT-GIT & $\begin{array}{l}\text { Negative QFT: IFN- } \gamma \text { (TB Ag - Nil) } \\
\leq 0.2 \\
\text { Positive QFT: IFN- } \gamma \text { (TB Ag - Nil) } \geq \\
0.7\end{array}$ & $\begin{array}{l}\text { QFT nonconverters: IGRA } \\
\text { negative at baseline and at } 6 \\
\text { months }\end{array}$ & $\begin{array}{l}\text { QFT reverters: IGRA positive at } \\
\text { baseline and IGRA negative at } \\
6 \text { months }\end{array}$ & $\begin{array}{l}\text { LTBI: IGRA positive at baseline } \\
\text { and at } 6 \text { months } \\
\text { IGRA converters: IGRA negative } \\
\text { at baseline and IGRA positive at } 6 \\
\text { months }\end{array}$ \\
\hline $\begin{array}{l}\text { Weiner et al. } \\
\text { (21) }\end{array}$ & The Gambia & $\begin{array}{l}\text { Based on sleeping proximity to the } \\
\text { index TB case and smear grade of } \\
\text { the index TB case }\end{array}$ & $\begin{array}{l}\text { Cohort 1: TST (2 TU, PPD } \\
\text { RT23, Statens Serum } \\
\text { Institut, Denmark) } \\
\text { Cohort 2: QFT-GIT }\end{array}$ & $\begin{array}{l}\text { TST: } 10 \mathrm{~mm} \\
\text { QFT: IFN- } \gamma(\text { TB Ag - Nil) at } 0.35 \\
\text { IU/ml }\end{array}$ & $\begin{array}{l}\text { Cohort } 1 \\
\text { TST nonconverters: TST }=0 \mathrm{~mm} \\
\text { at baseline and at } 3 \text { months. } \\
\text { Cohort } 2 \\
\text { Nonconverters: IFN- } \gamma \text { (TB Ag - } \\
\text { Nili) }<0.35 \text { IUS/mL at baseline and } \\
\text { at } 6 \text { months. }\end{array}$ & & $\begin{array}{l}\text { Cohort 1: (TST converters) } 0 \\
\text { mm at baseline and converted to } \\
\text { positive }>10 \mathrm{~mm} \text { by } 3 \text { months. } \\
\text { Cohort 2: (converters) IFN- } \gamma \text { (TB } \\
\mathrm{Ag}-\mathrm{Nil})<0.35 \mathrm{IU} / \mathrm{mL} \text { at baseline } \\
\text { and IFN- } \gamma(\text { (TB Ag }-\mathrm{Nili})>0.35 \mathrm{IU} / \\
\mathrm{mL} \text { at } 6 \text { months. }\end{array}$ \\
\hline
\end{tabular}


TABLE 1 | Continued

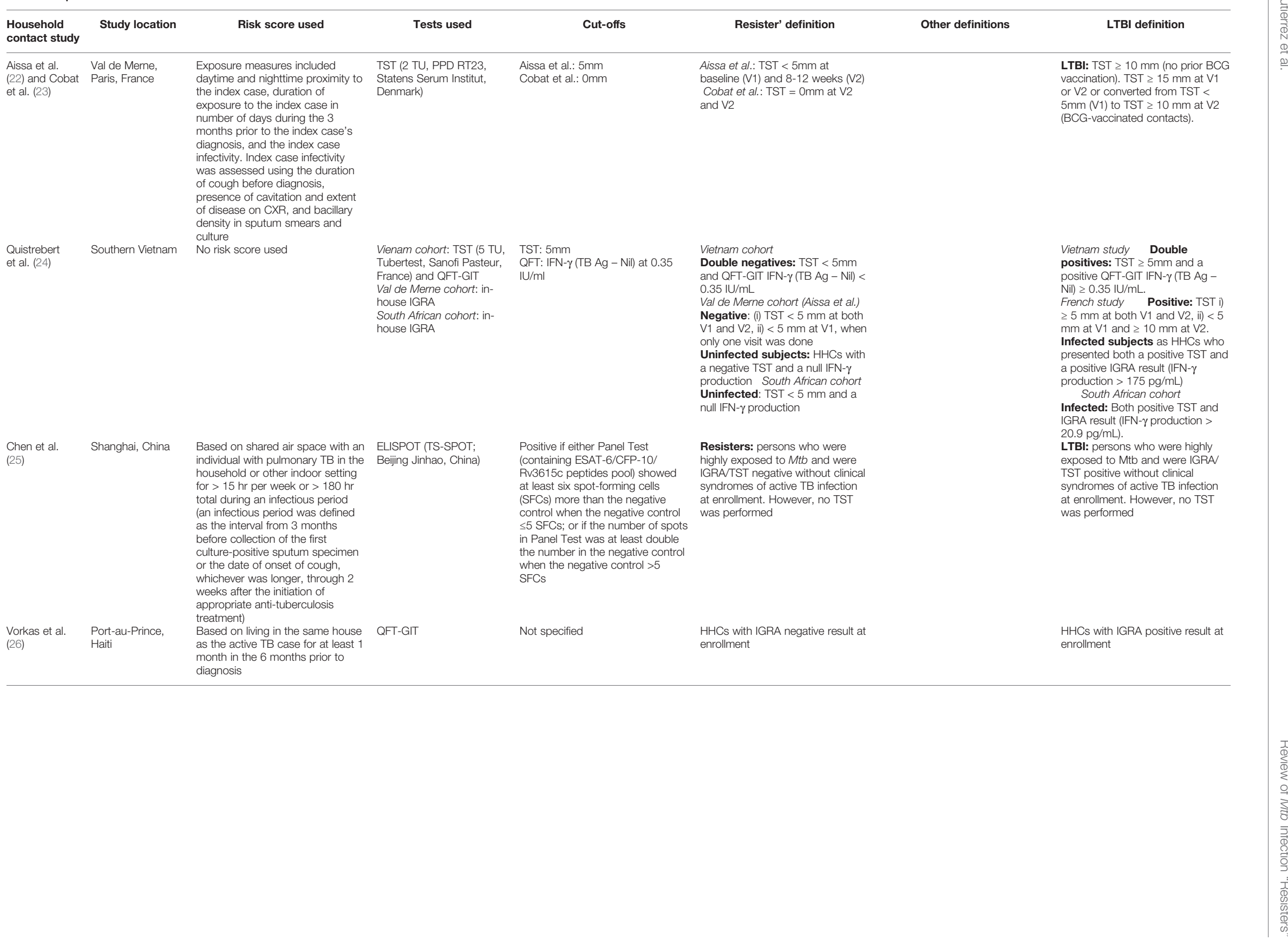


Cobat et al. Cape Town (27)

Gallant et al. Cape Town,

(28)

9)

Cape Town, South Africa

Mahomed et Worcester,

al. (30) South Africa
None. Risk is inferred from TST (2 TU, PPD RT23, community exposure in a high Statens Serum Institut, incidence environment Statens Serum Institut, None. Risk is inferred from TST (2 TU, PPD RT23, community exposure in a high Statens Serum Institut, incidence environment.

Denmark)

In-house IGRA

None. Risk is inferred from TST (2 TU, PPD RT23, community exposure in a high Statens Serum Institut, incidence environment. Denmark; 5 TU, PPD-S2, Tubersol, Sanofi Pasteur Limited, USA) QFT Gold Plus (QFT-Plus)

ST: Omm

TST: $5 \mathrm{~mm}$

In-house IGRA: 63 pg/mL

TST: $5 \mathrm{~mm}$

QFT-Plus:

Criteria for negative QFT-plus result:

1) $\mathrm{Nil} \leq 8.0$, and

2) TB1 minus Nil $<0.35$ or $\geq 0.35$ and $<25 \%$ of Nil value, and

3) TB2 minus $\mathrm{Nil}<0.35$ or 0.35 and $<25 \%$ of Nil value, and 4) Mitogen minus Nil $\geq 0.5$. Criteria for positive QFT-plus result either:

1) $\mathrm{Nil} \leq 8.0$, and

2) TB1 minus Nil $\geq 0.35$ and

$\geq 25 \%$ of Nil value, and

3) Any TB2 minus Ni

4) Any Mitogen minus $\mathrm{Ni}$

Or

1) $\mathrm{Nil} \leq 8.0$, and

2) Any TB1 minus Nil

3) TB2 minus Nil $\geq 0.35$ and

$\geq 25 \%$ of Nil value,

Risk was inferred from $\quad$ TST (2 TU, PPD RT23,

4) Any Mitogen minus Nil.

TST: $5 \mathrm{~mm}$

community exposure in a high Statens Serum Institut, $\quad$ QFT-GIT: IFN- $\gamma$ (TB Ag - Nil) at incidence environment. A Denmark)

subset of participants

QFT-GIT

reported current or prior

household contact, mostly

within three years of

enrollment.
TST $=0 \mathrm{~mm}$ at baseline

only.

Double negatives at a

single time point. TST <

$5 \mathrm{~mm}$ and IFN- $\gamma$ response

to BCG or PPD or ESAT-6

$<63 \mathrm{pg} / \mathrm{mL}$

\section{HIV-1-infected}

persistently TB,

tuberculin and IGRA

negative (HITTIN): HIV

persons who had

experienced a period of

very low CD4 counts, who

had no symptoms or

history of previous TB,

had three consecutive

negative IGRA readings,

and $\mathrm{a}$ TST $=0 \mathrm{~mm}$.
Focus of the study was on

converters/incident TB

cases. No definition of

given.
ST > Omm at baseline

only.

TST $\geq 5 \mathrm{~mm}, \mathrm{IFN}-\gamma$ response to BCG or PPD or ESAT-6 > 63 $\mathrm{pg} / \mathrm{mL}$.

HIV-1-infected IGRA positive tuberculin positive (HIT): HIV tpersons who hat experienced a period of very low CD4 counts, who had no symptoms

or history of previous

TB with two

consecutive positive GRA results and a TST $\geq 5 \mathrm{~mm}$.

Converters: IFN- $\gamma$ (TB $\mathrm{Ag}-\mathrm{Nil})>0.35 \mathrm{IU} / \mathrm{m}$ and TST $\geq 5 \mathrm{~mm}$ at baseline measurement. $50 \%$ had active followup (every 3 months), and $50 \%$ had passive follow-up (at 2 year 


\begin{tabular}{|c|c|c|c|c|c|c|c|}
\hline $\begin{array}{l}\text { Community- } \\
\text { based study }\end{array}$ & Study location & Risk score used & Tests used & Cut-offs & Resister' definition & Other definitions & LTBI definition \\
\hline $\begin{array}{l}\text { Nemes et al. } \\
(31)\end{array}$ & $\begin{array}{l}\text { Worcester, } \\
\text { South Africa }\end{array}$ & $\begin{array}{l}\text { Risk was inferred from } \\
\text { community exposure in a high } \\
\text { incidence environment. A } \\
\text { subset of participants } \\
\text { reported current or prior } \\
\text { household contact, mostly } \\
\text { within three years of } \\
\text { enrollment. }\end{array}$ & QFT-GIT & $\begin{array}{l}\text { QFT-GIT: IFN- } \gamma(\text { TB Ag - Nil) at } \\
0.2,0.35 \text { and } 0.7 \mathrm{IU} / \mathrm{ml}\end{array}$ & $\begin{array}{l}\text { Stringent } \\
\text { nonconverters: IFN- } \gamma \text { (TB } \\
\text { Ag }-\mathrm{Nil})<0.2 \mathrm{IU} / \mathrm{ml} \text { at } \\
\text { baseline, day } 360 \text {, and } \\
\text { day } 720 \text {. }\end{array}$ & $\begin{array}{l}\text { Stringent QFT persistent } \\
\text { positives: IFN- } \gamma \text { (TB Ag - } \\
\text { Nil) }>0.7 \mathrm{IU} / \mathrm{ml} \text { at baseline, } \\
\text { day } 360 \text {, and day } 720 \text {. } \\
\text { "Uncertain" converters: } \\
\mathrm{IFN}-\gamma(\mathrm{TB} \mathrm{Ag}-\mathrm{Nil})<0.35 \\
\mathrm{IU} / \mathrm{ml} \text { at baseline, and IFN- } \gamma \\
>0.35 \mathrm{IU} / \mathrm{ml} \text { at day } 360 \text {, } \\
\text { with at least one result } \\
\text { within the uncertainty zone } \\
\text { of } 0.2-0.7 \mathrm{IU} / \mathrm{ml} \text {. }\end{array}$ & $\begin{array}{l}\text { Stringent converters: } \\
\text { IFN- } \gamma(\text { TB Ag }-\mathrm{Nil})<0.2 \\
\text { at baseline and }>0.7 \text { at } \\
\text { day 360). }\end{array}$ \\
\hline $\begin{array}{l}\text { Andrews } \\
\text { et al. (32) }\end{array}$ & $\begin{array}{l}\text { Worcester, } \\
\text { Ceres \& } \\
\text { Robertson, } \\
\text { South Africa }\end{array}$ & $\begin{array}{l}\text { None. Risk is inferred from } \\
\text { community exposure in a high } \\
\text { incidence environment. }\end{array}$ & QFT-GIT & $\begin{array}{l}\text { QFT-GIT: IFN- } \gamma \text { (TB Ag - Nil) at } \\
0.35 \text { and } 4.0 \mathrm{IU} / \mathrm{ml}\end{array}$ & $\begin{array}{l}\text { Nonconverters: IFN- } \gamma \\
\text { (TB Ag - Nil) }<0.35 \mathrm{IU} / \mathrm{ml} \\
\text { at baseline, day } 336 \text { and } \\
\text { end of study. }\end{array}$ & & $\begin{array}{l}\text { Converters: IFN- } \gamma \text { (TB } \\
\text { Ag }-\mathrm{Nil})>4.00 \mathrm{IU} / \mathrm{ml} \text { at } \\
\text { baseline, day } 336 \text { and } \\
\text { end of study. }\end{array}$ \\
\hline $\begin{array}{l}\text { Simmons } \\
\text { et al. (33) }\end{array}$ & $\begin{array}{l}\text { North West } \\
\text { Province, South } \\
\text { Africa }\end{array}$ & $\begin{array}{l}\text { None. Risk is inferred from } \\
\text { work exposure in gold mines, } \\
\text { a high incidence environment. }\end{array}$ & $\begin{array}{l}\text { TST (2 TU, PPD RT23, } \\
\text { Statens Serum Institut, } \\
\text { Denmark) } \\
\text { QFT-Plus }\end{array}$ & $\begin{array}{l}\text { TST: Omm and } 5 \mathrm{~mm} \\
\text { QFT-Plus: Both antigen tube } \\
\text { readings of IFN- } \gamma(\mathrm{TB} \mathrm{Ag}-\mathrm{Nil}) \text { at } \\
0.35 \mathrm{IU} / \mathrm{ml}\end{array}$ & $\begin{array}{l}\text { "Uninfected" : Miners } \\
\text { who had a negative QFT- } \\
\text { Plus up to one year after } \\
\text { baseline. A stricter } \\
\text { definition was also used } \\
\text { as those with a negative } \\
\text { QFT-Plus and TST = } 0 \\
\text { mm after one year of } \\
\text { follow-up. }\end{array}$ & & $\begin{array}{l}\text { "TB infected": Miners } \\
\text { who had a positive } \\
\text { QFT-Plus up to one } \\
\text { year after baseline. A } \\
\text { stricter definition was } \\
\text { also used as those with } \\
\text { a postive QFT-Plus and } \\
\text { a TST > 5mm after one } \\
\text { year of follow up. }\end{array}$ \\
\hline Li et al. (34) & Beijing, China & $\begin{array}{l}\text { None. Risk inferred from } \\
\text { working at Beijing Chest } \\
\text { Hospital } \geq 3 \text { years }\end{array}$ & $\begin{array}{l}\text { ELISPOT (T.SPOTTB; } \\
\text { Oxford Immunotec) }\end{array}$ & $\begin{array}{l}\text { ELISPOT } \geq 24 \text { spots for ESAT-6, } \\
\text { CFP-10, or both }\end{array}$ & $\begin{array}{l}\text { "Highly exposed but } \\
\text { uninfected" (HEBUI): } \\
\text { Negative ELISPOT at } \\
\text { baseline only }\end{array}$ & & $\begin{array}{l}\text { "Latent": Positive } \\
\text { ELISPOT at baseline } \\
\text { only }\end{array}$ \\
\hline
\end{tabular}




\section{Bandung, Indonesia}

This HHC study by Verral et al. sought to outline characteristics and associated risk factors of "early clearers" of $M t b$ infection $(16,17,35)$. The HHCs for this study were recruited as part of the TANDEM project and originated in Bandung, one of the largest urban centers in Indonesia (36). The authors enrolled 1,347 HHCs of pulmonary TB index cases who were at least 5 years of age. Unlike the previous HHC studies, the authors only used the QFT test and the follow-up period was much shorter. The authors also used a different measure to evaluate the extent of exposure of HHCs. This score, which they derived using regression methods, was based on the index case's sputum smear grade, the presence of cavities and the extent of the CXR disease $(16,17,35)$. It also included the HHC's number of hours spent with the index case as well as the sleeping proximity. To categorize each HHC, Verral et al. used QFT tests at baseline and 14 weeks later. The cut offs used were those recommended by the manufacturer. The authors defined "early clearers" as those HHCs who had negative QFT results at the end of the follow-up period (Table 1) $(16,17,35)$.

Of the 1347 HHCs enrolled in the study, 490 were QFT negative at baseline and qualified for a follow up test. Of these, $317(64.7 \%)$ had a subsequent negative QFT result and were labeled "early clearers" and 116 (23.7\%) had a positive QFT result and were labeled "converters". The rest could not be reached for a repeat test, had indeterminate results, had active disease or unevaluated symptoms of TB. The authors point out that the rate of "early clearers" in this particular study $(\sim 25 \%)$ was similar to those found in the cohorts from Uganda (14\%) and The Gambia (45\%) $(6,18)$. "Early clearers" had lower measures of exposures and, along with converters, were younger than those who had a positive QFT test at baseline.

\section{The Gambia}

There are four HHC studies from The Gambia that provide insight in the natural progression of $M t b$ infection. The first study by Hill et al. took place in Banjul and used the ELISPOT test and TST to define phenotypes while the study by Weiner et al. utilized the QFT and TST $(18,21)$. Coulter et al. and Medawar et al., utilized QFT only $(19,20)$.

Hill et al. analyzed the test results of 558 HHCs who were at least 15 years of age. These HHCs underwent 3 ELISPOTs at baseline, at 3 months and at 18 months (16). In addition, all HHCs also underwent a TST (2 TU, PPD RT23, Statens Serum Institut, Denmark) at baseline and a "subcohort" of 196 consecutively recruited HHCs also underwent a repeat TST at 18 months. The authors used a more stringent cut off for the ELISPOT than is recommended by the manufacturer. A positive TST required an induration of at least $10 \mathrm{~mm}$ plus an increase in such induration of at least $6 \mathrm{~mm}$. Using the ELISPOT, the authors identified 97 (17\%) HHCs who had three negative results during the 18-month follow-up. In the "subcohort" of 196 HHCs who underwent both ELISPOT and TST testing, 27 (14\%) had consistently negative results after 18 months (Table 1).

Coulter et al. recruited 31 household TB contacts of 10 active TB index cases and classified them as LTBI, IGRA converters or non-converters, based on an in-house IGRA taken at baseline and 6 months later (19). Whole blood was stimulated by PPD, ESAT-6 and CFP-10. No details are provided on the threshold for IFN- $\gamma$ positivity. Ten participants (32\%) tested baseline IGRA positive and were defined as LTBI. Eleven (35\%) participants who tested IGRA negative at baseline and remained negative at follow-up were defined as IGRA non-converters. Ten (32\%) IGRA converters, who tested baseline negative and converted to positive at 6 months were also included. Exposure was measured by the smear grade of the index patient as well as sleeping proximity to the index patient (19). In a second study the group selected HHC from another longitudinal HHC cohort study (20). High exposure was defined by sleeping proximity and only persons sleeping in the same room as the index case was included. HHCs were seen at baseline and 6 months later. Seventeen (25\%) were defined as "QFT nonconverters" based on 2 negative readings, $14(21 \%)$ as "QFT converter" based on a negative at baseline and positive after 6 months, $18(27 \%)$ as "QFT reverter" based on positive at baseline and negative after 6 months and lastly $18(27 \%)$ as "LTBI" based on 2 positive readings. A QFT was considered negative if IFN- $\gamma$ (TB Ag $\mathrm{Nil})<0.2 \mathrm{IU} / \mathrm{ml}$ and positive if IFN- $\gamma(\mathrm{TB} \mathrm{Ag}-\mathrm{Nil})>0.7 \mathrm{IU} / \mathrm{ml}$, which avoided what they referred to as the "grey zone" (20). It is not clear whether the participants represented in these two studies originated from the same cohort.

The fourth and most recent study by Weiner et al. was a casecontrol study nested within the larger study of HHCs at Medical Research Council Unit The Gambia (21). The authors used the same TB exposure score as Coulter et al. $(19,21)$. Weiner et al. aimed to characterize the host transcriptomic, metabolic, and antibody responses to $M t b$ in "nonconverters" when compared to "converters". To do so, they established two different cohorts. In cohort 1, "nonconverters" were defined as HHCs who had a TST (2 TU, PPD RT23, Statens Serum Institut, Denmark) result of $0 \mathrm{~mm}$ at baseline and at the 3-month follow-up. In cohort 2, "nonconverters" were defined as HHCs who had a negative QFT test result at baseline and at the 6-month follow-up (Table 1) (21). Unfortunately, the authors did not provide the cut-off values they used to determine a negative QFT test result, nor did they mention the number of "nonconverters" identified.

\section{Val-de Marne, Paris, France}

This cohort of HHCs was described in multiple substudies aimed at characterizing the genetics of a $M t b$ infection resistance phenotype. They lived with pulmonary TB index cases for 3 months prior to their TB diagnosis and were recruited between April 2004 and January 2009. Between April 2004 to December 2005, 325 index cases and 2009 HHCs were initially identified and described (22). Participants were seen for two visits. During the screening visit (V1) a TST (5 TU, Tubertest, Sanofi Pasteur, France) was administered and blood was taken for an in-house IGRA. A repeat TST was administered 8-12 weeks later during visit 2 (V2).

A negative TST was defined as a TST reading $<5 \mathrm{~mm}$ at both $\mathrm{V} 1$ and $\mathrm{V} 2$ or a single reading $<5 \mathrm{~mm}$ if only one visit (V1) was completed. In contacts without prior BCG vaccination a positive TST reading was defined as $\geq 10 \mathrm{~mm}$. A TST reading was 
considered positive in BCG-vaccinated persons if it was $\geq 15 \mathrm{~mm}$ at both $\mathrm{V} 1$ or $\mathrm{V} 2$ or $<5 \mathrm{~mm}$ at $\mathrm{V} 1$ and converted to $\geq 10 \mathrm{~mm}$ at V2 (22). The authors also collected exposure measures of HHCs. These included daytime and nighttime proximity to the index case, duration of exposure to the index case in days during the 3 months prior to the index case's diagnosis, and the index case infectivity. Index case infectivity was assessed using the duration of cough before diagnosis, presence of cavitation and extent of disease on CXR, and bacillary density in sputum smears and culture $(22,24)$.

Aissa et al. identified 1575 contacts who completed the screening process. Of these contacts a total of $1,150 / 1,575$ (73\%) remained uninfected, $410(26 \%)$ had latent infection and 15 (1\%) had active TB. Later and by using more stringent TST definitions, a total of $84 / 540(15.6 \%)$ HHCs with TST readings of $0 \mathrm{~mm}$ at both visits, were defined and was used to replicate findings in the Sequella cohort which was recruited in South Africa and is described under community-based studies (Table 1) (23).

An additional in-house IGRA was later described in the same cohort $(24,37)$. The in-house IGRA was defined to measure IFN$\gamma$ production after stimulating peripheral blood mononuclear cells (PBMCs) with ESAT-6 and null production of IFN- $\gamma$ was defined as a negative IGRA. A positive IGRA result was defined as IFN- $\gamma>175 \mathrm{pg} / \mathrm{mL}$ (24). A negative TST was defined as a TST reading $<5 \mathrm{~mm}$ at both $\mathrm{V} 1$ and $\mathrm{V} 2$ or a single reading $<5 \mathrm{~mm}$ if only one visit (V1) was completed. A TST reading was considered positive if it was $\geq 5 \mathrm{~mm}$ at both $\mathrm{V} 1$ and $\mathrm{V} 2$ or < $5 \mathrm{~mm}$ at V1 and converted to $\geq 10 \mathrm{~mm}$ at V2 (24).

Contacts were defined as $M t b$ infection "resisters" if they had a negative TST and null IFN- $\gamma$ production, irrespective of previous BCG status. In total, 33/664 (5\%) were identified as $M t b$ uninfected (TST negative and IGRA null). There were 147/ $664(22 \%)$ infected (TST positive and IGRA positive) persons and $484 \mathrm{HHC}$ who had discordant results or missing information. This cohort was used to validate loci identified in the HHC study in Vietnam $(22,24)$.

\section{Southern Vietnam}

This study included 1,108 HHCs of 466 pulmonary TB cases from 2010 to 2015 in an endemic region of Southern Vietnam (24). The objective of the study was to characterize the genetics of a TST and QFT negative $M t b$ resister phenotype. However, participants were not followed or defined longitudinally. Participants were invited for a baseline TST (5 TU, Tubertest, Sanofi Pasteur, France) and QFT test. A negative TST was defined as a TST reading $<5 \mathrm{~mm}$. QFT results were defined according to the manufacturer's instruction (24). Although the authors defined the HHC subjects included in the study as being at high risk of infection, they did not provide information on any measures of exposure that they may have used to make this determination.

The study defined resistance to $M t b$ infection as a negative TST and IGRA reading at a single time point ("double negatives"). This group was compared to the group classified as $M t b$ infected i.e. a positive TST and IGRA reading ("double positives"). In total, 188 (17\%) "double negatives" and $512(46 \%)$ "double positives" were identified, as well as 408 participants with discordant results who were excluded (24).

\section{Shanghai, China}

The cross-sectional study by Chen et al. sought to identify the CD69 expression profiles of a number of different phenotypes, including "resisters" (25). The authors defined "resisters" as individuals who were close contacts to TB index cases with persistently negative TST/IGRA results despite prolonged exposure. Prolonged exposure was defined as sharing air space with an individual with pulmonary TB in the household or other indoor setting for $>15 \mathrm{~h}$ per week or $>180 \mathrm{~h}$ total during an infectious period. The infectious period was defined as the interval from 3 months before collection of the first culturepositive sputum specimen or the date of onset of cough, whichever was longer, through 2 weeks after the initiation of appropriate TB treatment. However, the authors only used the ELISPOT assay at baseline (according to the manufacturer's instructions) and did not confirm the persistence of this result with subsequent tests. Based on these definitions, Chen et al. identified 13 "resisters" (25).

\section{Port-au-Prince, Haiti}

A cross-sectional study design was utilized to recruit HHCs from high transmission risk households (26). High risk of exposure of the HHCs was defined as sleeping in the same house as the TB index case for at least one month during the six months prior to the index case diagnosis. HHCs were seen at baseline and 6 months later and were screened for LTBI using QFT. Unfortunately, the authors did not provide the QFT cut-offs used in their study. At baseline, 19 (61\%) HHCs tested QFT positive and $12(39 \%)$ tested QFT negative. All of the twelve (39\%) initially negative HHC remained IGRA negative on both visits and they were labeled as "TB healthy household contacts" who had "resisted infection" (26).

\section{Community Studies}

In high $\mathrm{TB}$ burden settings, contact outside the household accounts for the majority of TB transmission in these settings. This occurs especially in cases of prolonged stay in low socioeconomic communities with a high burden of TB and HIV (38, 39). Some activities associated with transmission include drinking in social groups, using public transportation, school and workplace exposures (38-46). Individuals who are severely immunocompromised, as with $\mathrm{HIV}$-infection, are more susceptible to progress to TB (47-49).

Genotype and phenotypic drug susceptibility testing in the Western Cape, South Africa, show that considerable community transmission occurs in children $<13$ years with household $\mathrm{TB}$ transmission cases only contributing to around $8-19 \%$ (46, 5053). Age can be used as a proxy for exposure frequency with at least $80 \%$ of individuals converting to positive TST reactions by the age of $30(28,45)$. High $M t b$ infection transmission rates in a high burden community show the importance of utilizing community-based research in these settings $(45,54,55)$. 


\section{Sequella Study, Cape Town, South Africa}

The Sequella study recruited 475 healthy, HIV-uninfected children and adolescents from 155 nuclear families from local clinics in two suburbs in Cape Town, South Africa (28). Blood was collected for an in-house IGRA and TST (2 TU, PPD RT23, Statens Serum Institut, Denmark) at baseline only. TST measurements were recorded as negative if TST $<5 \mathrm{~mm}$. IFN$\gamma$ was measured after whole blood was stimulated with live BCG, PPD or ESAT- 6 and positive responders were initially defined as IFN- $\gamma$ responses of $>62 \mathrm{pg} / \mathrm{mL}$ (28).

The resister phenotype was defined as participants with double negative results at a single time point and were not longitudinally followed. A total of 164 (38\%) were classified as TST negative or TST $<5 \mathrm{~mm}$ with 162 having TST readings of $0 \mathrm{~mm}$ and 260 with readings $\geq 5 \mathrm{~mm}$. The double negatives identified were as follows: BCG negative $(n=15)$, PPD negative $(n=26)$ and ESAT-6 negative $(n=81)(28)$.

More recently this cohort was used to validate findings in the aforementioned Vietnamese cohort (24). Mtb infection resisters were now defined as uninfected subjects with a negative TST (< $5 \mathrm{~mm}$ ) and a null IFN- $\gamma$ production [128/415 (31\%)], and infected subjects as those with both positive TST and IGRA result (IFN- $\gamma$ production $>20.9 \mathrm{pg} / \mathrm{mL}$ ) $[152 / 415(37 \%)]$. A third of the participants $[135 / 415(33 \%)]$ had discordant results.

\section{Cape Town, South Africa}

The ResisTB study is a community based case-control study conducted in Cape Town, South Africa (29). Participants were recruited from ART clubs at HIV clinics in Cape Town.

The "resistance" phenotype was defined as HIV-1-infected persistently TB, tuberculin and IGRA negative (HITTIN). All participants had to be HIV positive persons aged 35 to 60 years and living in an area of high transmission of $M t b$, i.e., Cape Town. In addition, the criteria included a history of living with a low CD $4+$ count (either with two CD4+ $<350$ cells $/ \mathrm{mm}^{3}$ counts at least 6 months apart or a single CD $4+$ count $<200$ cells $/ \mathrm{mm}^{3}$ ) prior to initiating ART. During this period, these individuals would have been extremely susceptible to infection and disease. By the time of enrollment all participants were immune reconstituted on $\mathrm{ART}$ for at least one year with the most recent CD4+ count $>200$ cells $/ \mathrm{mm}^{3}$ (29).

Participants were screened with a QuantiFERON-TB Gold Plus (QFT-Plus) in-tube test and were classified as IGRA positive or negative according to the manufacturer's instructions. Once identified participants were longitudinally followed-up. Individuals who tested IGRA negative were re-contacted on average $203 \pm 151$ days later for a second IGRA and TST administration (5 TU, PPD-S2, Tubersol, Sanofi Pasteur Limited, USA; 2 TU, Tuberculin PPD RT23, Statens Serum Institute, Denmark). The TST was read 3 days later and after this was done, a third IGRA was taken. Individuals in the final case group were designated HITTIN if they had three consecutive, negative IGRA tests and a negative TST reading $(\mathrm{n}=48)$ (Table 2). In parallel, a subset of control participants with an initial positive IGRA test were re-contacted for a second IGRA after an average of $292 \pm 70$ days. Those participants who tested IGRA positive in two consecutive tests (IGRA double+) and displayed a TST $>5 \mathrm{~mm}$ are defined as HIV-1-infected IGRA positive tuberculin positive (HIT, $\mathrm{n}=35$ ) (29).

\section{Worcester, South Africa}

An adolescent youth cohort was recruited from local schools in Worcester, Western Cape, South Africa, during May 2005 until April 2007 (30, 31, 56-58). The TB notification rate in Worcester, was 1,400 cases per 100,000 in 1996 . In total 6,363 adolescents aged 12-18 years (median 15yr, IQR:14-16) were enrolled into the cohort. The study included a majority younger participants $\leq 15$ years old [56.5\% (3603/6363)] and females [54.3\% (3458/6363)] (58). Most of the participants, 1,055 of the 1,728 who had a current and prior household contact, reported the contact was within three years of the enrolment. Participants were screened with baseline TST (2 TU, Tuberculin PPD RT23, Statens Serum Institute, Denmark)) and QFT.

Nemes et al. investigated the consistency of serial QFT testing algorithms and included a more refined QFT conversion definition [a decrease from the manufacturer's guidelines of IFN- $\gamma(\mathrm{TB}$ Ag $-\mathrm{Nil})<0.35 \mathrm{IU} / \mathrm{ml}$ to $<0.2 \mathrm{IU} / \mathrm{ml}$ and an increase from IFN- $\gamma(\mathrm{TB} \mathrm{Ag}-\mathrm{Nil})>0.35$ to $>0.7 \mathrm{IU} / \mathrm{ml}]$ to control technical and immunological variability that may occur within the "uncertainty zone" of $0.2-0.7 \mathrm{IU} / \mathrm{ml}$ (31).

The QFT results for participants in cohort 1 were classified according to the more stringent cutoffs compared to the manufacturer's guidelines and were grouped into four categories. Stringent QFT nonconverters were defined as IFN- $\gamma$ (TB Ag - Nil) < $0.2 \mathrm{IU} / \mathrm{ml}$ at baseline, day 360, and day 720 . Stringent QFT persistent positives were defined as IFN- $\gamma$ (TB Ag - Nil) > $0.7 \mathrm{IU} / \mathrm{ml}$ at baseline, day 360 , and day 720 . Stringent QFT converters were defined as IFN $-\gamma(\mathrm{TB}$ Ag $-\mathrm{Nil})<0.2 \mathrm{IU} / \mathrm{ml}$ at baseline and IFN- $\gamma>0.7 \mathrm{IU} / \mathrm{ml}$ at day 360 . Lastly "uncertain" converters were defined as IFN- $\gamma(\mathrm{TB} \mathrm{Ag}-\mathrm{Nil})<0.35 \mathrm{IU} / \mathrm{ml}$ at baseline, and IFN- $\gamma>0.35 \mathrm{IU} / \mathrm{ml}$ at day 360 , with at least one result within the uncertainty zone of $0.2-0.7 \mathrm{IU} / \mathrm{ml}$ (Table 2). A total of $n=648 / 2,432$ individuals were identified as stringent nonconverters and 989/2,432 were stringent persistent positives (31).

Applying a more stringent cutoff for a negative QFT result in cohort 1 improved concordance between TST and IGRA results. In the group with a negative QFT reading between $0.2-0.34 \mathrm{IU} /$ $\mathrm{ml}, 53 \%$ had a discordant positive TST result, compared to $15 \%$ in the group with QFT IFN- $\gamma$ values $<0.2 \mathrm{IU} / \mathrm{ml}$. In total $43 \%$ of those with QFT IFN- $\gamma$ values between $0.2-0.7 \mathrm{IU} / \mathrm{ml}$ had discordant TST and QFT results, with $85 \%$ concordance in those with values $<0.2 \mathrm{IU} / \mathrm{ml}$ and $>0.7 \mathrm{IU} / \mathrm{ml}(31)$.

Importantly, stringent QFT nonconverters in cohort 1 had lower risk of developing TB disease (TB incidence 0.16 cases $/ 100$ Person-Years) than stringent QFT converters (TB incidence 1.60 cases/100 Person-Years, $\mathrm{p}=0.0003$ ) and stringent persistent positives (TB incidence 0.97 cases/100 Person-Years, $\mathrm{p}=0.005$ ). Due to immunological and technical assay variability "uncertain" QFT converters likely have a higher number of false positive converters since this group does not have a significantly different risk of TB disease compared to stringent nonconverters (TB incidence 0.66 cases/100 Person-Years, $\mathrm{p}=0.229$ ) (31). 


\section{Rural Western Cape (Ceres, Robertson, Worcester), South Africa}

Participants were recruited to a MVA85A tuberculosis vaccine trial during 2009 to 2011 in rural Western Cape, South Africa (32). The trial enrolled young children between 18-24 weeks old, with a median age of 20.4 weeks (IQR 19.3-22.0).

All children were screened with a baseline QFT. Similarly, to the previously described study stricter QFT cut-off values were applied (Table 2). A revised positive QFT test was defined as a IFN- $\gamma(\mathrm{TB}$ Ag $-\mathrm{Nil})>4.00 \mathrm{IU} / \mathrm{ml}$ and a negative QFT as $<0.35$ $\mathrm{IU} / \mathrm{ml}$. Conversion was defined as a baseline negative QFT which was followed by a positive QFT. They defined an "uncertainty zone” of a QFT reading between 0.35-4.00 IU/ml. In total 2772/ 2797 of the children had a baseline negative QFT result. After 336 days, 2,512/2,772 (91\%) had a repeat QFT and 2,327 (93\%) remained QFT negative. QFT converters had higher risk of developing TB disease (TB incidence 28.0 cases/100 PersonYears) compared to those in the "uncertainty zone" (IRR 11.4; $\mathrm{p}=0.00047$ ) and QFT non-converters (IRR 42.5; $\mathrm{p}<0.0001$ ) (32).

This study did not use TST in conjunction with the QFT test. The generalizability is limited to young infants only, and because of young age, they likely have not been exposed to prolonged and sufficient $M t b$ exposure. Infants who developed active disease by day 336 were not included in the analysis and those who converted were given IPT. The authors suggest that QFT IFN- $\gamma$ values $\geq 4.00 \mathrm{IU} / \mathrm{ml}$ in young children should prompt increased clinical diagnostic vigilance and potential interventions to prevent TB.

\section{Gold Mines, South Africa}

In South African gold mines, $13 \%$ of HIV-uninfected and $45.5 \%$ of HIV-infected gold miners tested TST $=0 \mathrm{~mm}$ (59). Due to a very high $M t b$ infection pressure and TB transmission in gold mines, transmission modelling assumes at least one lifetime infection in all gold miners (60). A study of goldminers, describes the long term follow up of some of these miners (33, $59,61)$. Briefly, Simmons et al. analyzed a subset of 307 miners who were HIV-negative and had at least 15 years of mining experience in order to ascertain epidemiological factors associated with resistance to infection (Table 2). Both the QFT-Plus and TST (2 TU, PPD RT23, Statens Serum Institut, Denmark) were used during a one year follow up. The authors defined miners who were "uninfected" as those who had a negative QFT- Plus at baseline and one year later. They also used a stricter definition of "uninfected" as those miners who had a negative QFT- Plus and a TST $=0 \mathrm{~mm}$. at baseline and one year later. Based on the stricter definition, the authors found that $18.7 \%$ of miners of Black/African ethnicity included in this analysis remained "uninfected" using the stricter definition. There is likely a spectrum of "resistance" to $M t b$ infection and given a high enough $M t b$ infection pressure, as in gold mines, most individuals are likely to become infected (2).

\section{Beijing, China}

A group of healthcare workers (HCW) in a TB hospital in Beijing, China were screened for Mtb infection with ELISPOT (T.SPOTTB; Oxford Immunotec) (34). A test was considered positive if ELISPOT $\geq 24$ spots for ESAT-6, CFP-10, or both. HCW were only screened once at baseline. In total, 24 (50\%) of HCW were defined as "latently" infected with a positive ELISPOT. The other half, 24 (50\%) tested ELISPOT negative and were defined as "highly exposed but uninfected" (HEBUI). These HCW were enrolled if they had been working at the hospital for more than 3 years. Their work was considered high risk since standard infection control procedures such as wearing masks are not mandated, nor always followed (34).

\section{DISCUSSION}

Making comparisons across studies that have differing definitions of clinical groups of interest is a difficult proposition. A brief overview of the twenty studies presented in this review revealed seventeen different definitions for resistance to $M t b$ infection as measured by IGRA and TST. The definitions vary in a number of important categories, which include how the intensity and duration of exposure to $M t b$ was measured, the type of diagnostic tests and cut-offs used and the durability of the phenotype across different lengths of studies.

\section{Extent of Exposure}

One of the important aspects of a HHC study is the opportunity to characterize the extent of exposure to $M t b$. Unfortunately, only a minority of the HHC studies reviewed provided a good measure of this important factor. Stein et al. and Mave et al. utilized the same epidemiological risk score $(11,12,15)$. This score is composed of a number of questions that provides a good understanding of the extent of exposure (i.e. whether the HHC share the same room or bed as the index case, whether the index case is actively coughing, whether the index case has a smearpositive sputum, whether the index case see the HHC every day) $(11,12,15)$. The score can be used in both adult and pediatric populations. The use of this risk score allowed Stein et al. to make sure the extent of exposure would not differ between "resisters" and "converters" while Mave et al. included the score itself in their definition of resistance. Verral et al. also used an epidemiological risk score created specifically for their analysis using a logistic regression of exposure variables against QFT results. The resulting variable took into account both the intensity and duration of exposure (35). Of the studies that took place in The Gambia, Hill et al. did not use a risk score. On the other hand, Weiner et al. and Coulter et al. used a basic score composed of two variables (smear grade of the index case and the sleeping proximity to the index case), which they used to identify "nonconverters" and "converters" with the highest level of exposure $(19,21)$. Medawar et al. included HHC who were highly exposed based on sleeping in the same bedroom as the TB index case only (20). In another study, Vorkas et al. defined risk as a HHC who was sleeping in the same house as the TB case for at least a month during the 6 months before the index case was diagnosed (26). Finally, Chen et al. defined prolonged exposure as sharing air space with an individual with pulmonary TB in the household or other indoor setting for $>15 \mathrm{~h}$ per week or $>180 \mathrm{~h}$ total during a specific infectious period (25). The rest of the HHC 
studies, Cobalt et al., Jabot-Hanin et al., and Quistrebert et al., did not use a formal risk assessment of their participants as they concluded being a household contact living in the same residence as the index case would be enough to consider them at high risk of exposure. However, a household contact with a negative TST and/or QFT who qualifies for a study's definition of "resister" may simply be the result of an exposure which is low in intensity or short in duration (2). This is why it is important to establish a measure of exposure, such as a validated epidemiological risk score, that could be used across studies.

The intensity of $M t b$ exposure is difficult to define within the context of a community based study design. Participants are usually unknowingly exposed to $\mathrm{TB}$ cases in comparison to HHC studies where there are defined TB cases and contacts. In high TB burden communities, the intensity of $M t b$ exposure is therefore inferred from community based rather than household transmission.

The extent of $M t b$ exposure is mostly defined by the duration of exposure in the community based studies. Incorporating an epidemiological risk score could be useful to identify and quantify possible high risk activities participants could be involved with e.g. classifying the amount of time an individual works in a high risk environment as with the gold mine studies, time spent using public transport in high incidence settings, previous or current TB contact and living in overcrowded conditions. Assigning risk scores to these activities would be cumbersome and difficult to substantiate, since none of these factors operate independently. For community based studies cumulative exposure to $M t b$ occurs by working or living in a high TB incidence environment (62). Simmons et al. defined a group of HIV-uninfected miners who worked for a prolonged time ( $>15$ years) in South African gold mines which are known to be high TB risk environments $(33,59,61)$. They restricted their analysis to include African miners who were more at risk based on poor socioeconomic status, living in crowded hostels and working underground in more poorly ventilated areas. Li et al. included HCW who worked for more than 3 years in a TB hospital where mask wearing was not mandated (34). In comparison, the ResisTB, Sequella and the Worcester based studies recruited participants from known high TB incidence areas $(28,29,58)$. In addition, the ResisTB study used age as a proxy for exposure frequency and duration with older age (ages 35-60 years) representing a group who would have prolonged exposure in a high $\mathrm{TB}$ incidence environment (29). The results obtained from these community based studies are specific to the community described and one should be wary of making generalized conclusions.

\section{Diagnostic Tests}

The "resister" definition should include both a negative TST and IGRA test result. The predictive value of using both tests is highlighted by the Mahomed et al. cohort which showed that TB incidence rates were higher for those participants with a baseline positive TST $(\geq 5 \mathrm{~mm})$ and IGRA $(>0.35 \mathrm{IU} / \mathrm{ml})$ [0.6 cases per 100 person years (95\% CI $0.43-0.82), 0.64$ cases per 100 person years (0.45-0.87)], compared to participants who had baseline negative TST and IGRA results [0.22 cases per 100 person years (0.11-0.39), 0.22 cases per 100 person years $(0.12-0.38)]$ (30). Of the studies reviewed, eight of them used both of these tests in their definitions of resistance $(12,15,18,24,28-30,57)$, eight of them only used an IGRA test $(16,17,19,20,25,26,31,32,34,35)$ and three of them only used a TST $(23,24,27)$. Although Weiner et al. used both tests, they applied the TST to one cohort and the IGRA test to another cohort (21) (Tables 1 and 2).

A TST is a highly sensitive test and is a marker of TB immunoreactivity rather than a marker of infection (63). It is less specific than an IGRA and is known to have decreased specificity with false positives and cross-reactions to previous BCG vaccination and nontuberculous mycobacteria (NTM). Individuals with a negative TST may not have been sufficiently exposed to $M t b$, or they were exposed but cleared infection. This could be either due to their own immunity or after receiving $M t b$ sterilizing prophylactic therapy such as Isoniazid. It is therefore imperative that documentation of $M t b$ exposure is maximized in the resistance phenotype as persons with prolonged exposure are less likely to revert and tend to remain TST positive after isoniazid preventive therapy, or even after completing TB treatment (63-66). However, application or reading errors, in addition to immunosuppressed states such as HIV-infection, immunosuppressive drug treatment and malnutrition could also account for false negatives.

Phenotypes defined as "resisters" or so-called persistently TST negative likely contain heterogeneous subgroups as discussed above. To improve the specificity of the phenotype, a TST is combined with an IGRA test. TST and in vitro IFN- $\gamma$ assays do not measure similar aspects of host immunity and may depend on the host as well as the frequency and exposure setting of $M t b$ and NTM (28). In general, the proportion of individuals testing IGRA positive is lower than those having a positive TST and combining the two tests gives a stricter resistance definition (67).

There are two forms of commercially based IGRA tests available. One is based on an enzyme-linked immunosorbent assay (ELISA) and the other is an enzyme-linked immunosorbent spot (ELISPOT) assay. IGRA performs better as a marker of $M t b$ infection in a high compared to a low TB burden community and shows comparable reversion and conversion rates to TST (56). The studies covered in this review used different IGRA tests in their work. Galant et al. and the Val de Merne cohort described by Jabot-Hanin et al. and Quistrebert et al., as well as Coulter et al. described in-house IGRAs $(19,24,28,37)$. Hill et al., Chen et al. and Li et al. used an ELISPOT and the rest, except for Kroon et al. and Simmons et al. who used QFT-Plus, used QFT in their studies $(18,25,29,34)$. The latest QFT-Plus removed TB-7.7 from the assay and added a TB antigen tube with peptides which measure CD8+ cytotoxic T lymphocyte responses (68). This assay was developed to improve the lack of sensitivity of the QFT test, especially in HIV-infected persons. However, more studies are still needed to show that this is indeed the case (69). QFT-Plus shows good agreement with QFT (70-73) with mostly similar specificity and sensitivity (74-76). In addition, good concordance is seen between QFT, QFT-Plus and T.SPOT $(73,77)$.

IGRA results should be interpreted within the scope of performing the tests in low vs high TB burden settings, the immunocompetency of the patient and the range of output 
values from the tests $(75,78,79)$. Output values often fall within a zone of uncertainty, defined as the total IFN- $\gamma$ reading between 0.2-0.7 IU/ml after subtracting nil from TB Ag readings (31). Most participants with reversions tend to fall in this zone (31). This has been seen in QFT as well as QFT-Plus (73). Values falling in this zone are usually related to host immunological or technical variability $(56,80)$. This could also be indicative of participants who were recently infected and then possibly cleared infection. More reliable cut-offs for IGRA negativity set as values less than $0.2 \mathrm{IU} / \mathrm{ml}$ and $>0.7 \mathrm{IU} / \mathrm{ml}$ for a positive IGRA have been suggested $(20,31)$. Using these stricter definitions, they show that stringent nonconverters are less likely to develop TB over 2 years compared to recently converted or persistently QFT positive persons $(31,56)$. This would need to be evaluated within the context of the QFT-Plus assay which requires a value $25 \%$ greater than the nil value and a reading greater than the current standard cutoff of $0.35 \mathrm{IU} / \mathrm{ml}$ in either the TBAg1 or TBAg2 tube to be considered positive. Except for Nemes et al., all of the definitions for resistance in the literature use the established standard cutoffs when using IGRAs.

Finally, when using TST and IGRA tests, it is important to consider and collect information on factors that are associated with a positive result. For example, associations with smoking and diabetes have been established with positive TST and IGRA (8184). Socio-economic factors such as low income and education, male sex, race, older age and HHC were identified as predictive factors for positive TST and IGRA results by Mahomed et al. (30). No significant differences were seen for socio-economic factors nor other factors such as smoking, BMI, and diabetes between HIT and HITTIN in the study by Kroon et al. (29). Mave et al. and Vorkas et al. also report no significant differences in demographic factors or clinical characteristics between converters and nonconverters (85). Simmons et al. report a BMI $>30$ to be a risk factor for testing IGRA or TST positive (36). Similarly, Igo et al. found an association between a persistently TST negative result and a lower prevalence of lean mass wasting in the Uganda cohort. This is also in line with what some other studies have found $(73,86)$. Verrall et al. highlighted important evidence that BCG-vaccination provides dose dependent protection against IGRA conversion in HHC (16, 17). This protection effect is not seen in cases of high TB exposure and decreases with older age $(16,17,87)$. In studies which show documented previous BCG vaccination or scars, no significant differences were seen between converters and nonconverters (12, 21), nor did a previous BCG show increased risk of conversion in Hill et al. (18). In addition, it would be of important for HHC studies to report the $M t b$ genotype as different strains are linked to TB clustering and variation in transmission (88). Verrall et al. reports an increased risk of conversion based on $M t b$ lineage, compared to Stein et al. who reported no difference in conversion based on $M t b$ lineage $(12,16,17,89)$.

\section{Durability of Responses}

Based on previous epidemiological studies, and as suggested by Stein et al., resistance to $M t b$ does not appear to be absolute (12, 90, 91). In fact, there appears to be a threshold above which infection will be acquired due to a high enough intensity of exposure (2). Considering the shortcomings aforementioned of both the TST and
IGRA tests, long term follow-up composed of multiple testing is imperative to evaluate the durability of the results. With an average follow up time of close to 10 years, Stein et al. provides sufficient time to evaluate their definition of resistance. This study also showed that the majority of conversions happened by month 3 of follow-up (9.8\%), with 2.2\% converting between 3-6 months and even still some $(0.7 \%)$ converted after 6-12 months. Most of the individuals in this study remained both TST and QFT negative despite the long follow-up. Although it is not clear how the HHCs' exposure varied in between the original and the follow-up study, since the participants continued living in a highly endemic area, we can presume that this did not change much. Based on these results, Stein et al. concluded that the "resister" phenotype is robust (12).

Similarly, the studies performed by Mave et al., Kroon et al., and Simmons et al. used both tests serially throughout a followup period of approximately year, which is an appropriate amount of time to capture conversions to LTBI or active disease $(6,15$, 29). Of note, Mave et al. concluded that "pLTBI-" are rare and "resisters" are even rarer among HHCs. However, they attributed the low prevalence of these phenotypes partly to the more stringent cut-off use for the TST (15). Although not statistically significant, prevalence of the "pLTBI-" phenotype among children declined as age increased, which could certainly be the result of increased extent of exposure. Andrews et al. also had a sufficiently long follow-up of at least 336 days, however, the subjects were toddlers who were less than 2 years of age at enrollment (32). Both Nemes et al. and Mahomed et al. provided data on at least 2 years of either passive or active follow-up of adolescents with a maximum total time of 3.8 years $(30,31)$. A few studies followed participants between three to six months, a time when the majority of conversions would occur $(23,24,26$, $35,37)$. The rest of the studies were cross-sectional in nature and only examined participants at a single time point $(27,28,34)$. Despite their limitations, cross-sectional studies such as Cobat et al., Gallant et al., and Quistrebert et al., are appropriate to generate hypotheses and continue to contribute to our growing understanding of this phenotype. However, the durability and robustness of that which is measured remains unknown, since only a single time point is taken into account. Further follow-up to confirm robustness of the phenotype is needed to fully understand the implications of these biologic findings.

\section{Can a Unified "Resister" Definition Exist?}

Differences based on extent of exposure, diagnostic tests and durability of responses orders different studies according to a spectrum of host resistance (Figure 1). Early clearance is hypothesized to involve innate clearance of $M t b$ prior to an adaptive immune response (35). Theoretically, early clearance captures early response in a phenotype exposed to $M t b$ in an environment where $M t b$ exposure can be measured. "Early clearance" may not be achieved with each exposure and depends on the index case infectivity, TB severity and duration of contact $(16,17)$. In comparison, longitudinal studies with a longer follow-up, capture a more extreme and robust phenotype (12). The more extreme cases might only be captured by a smaller and high TB risk group, e.g persons living with HIV, who are able to remain $\mathrm{TB}$ free despite persistent or high 


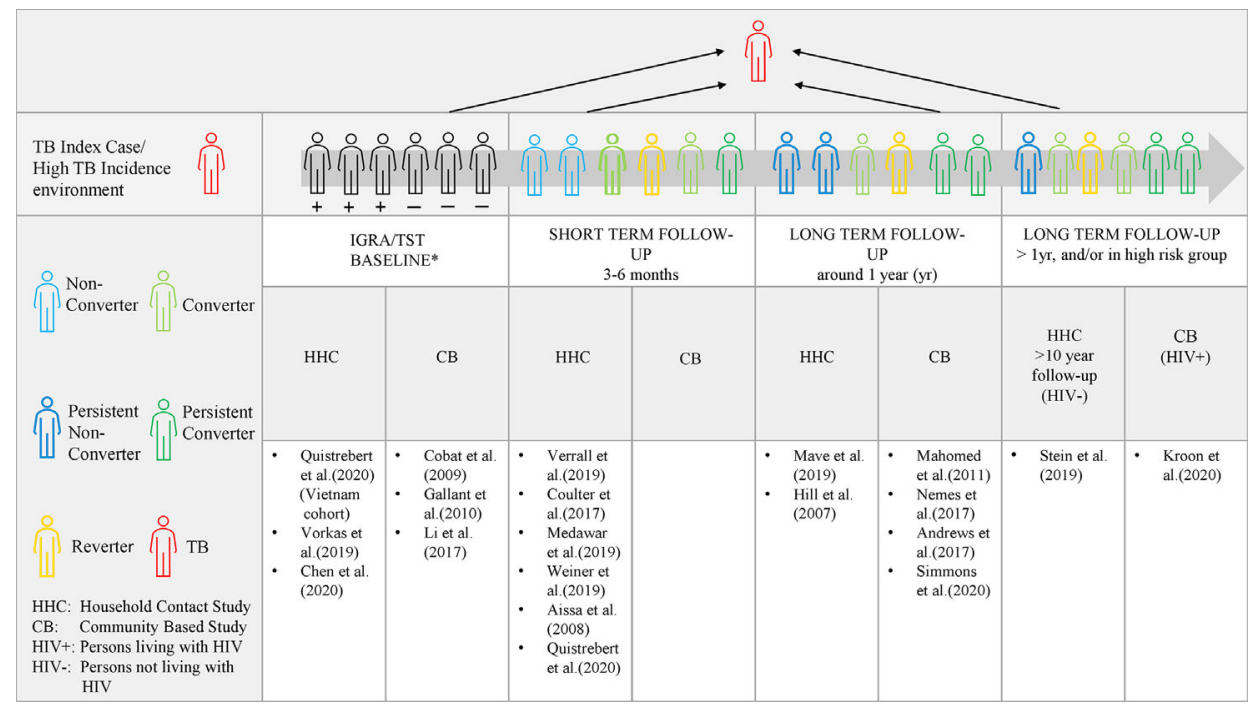

FIGURE 1 | The spectrum of IGRATST nonconverters. Evidence of protection to Mtb at a shorter time period in relation to the index case, allows the study of correlates of protection which may be overcome by exposure intensity and frequency (represented by the grey arrow). Long term follow-up allows for a more robust and extreme phenotype definition as in Stein et al. (followed for 10 years) and Kroon et al. (in persons living with HIV). Persistent non-conversion is not absolute and may eventually be overcome by time and very high levels of exposure or continuous exposure. *At baseline, individuals may test either TST/IGRA positive, negative or be discordant.

intensity exposure (29). The entire spectrum is of value and contributes to our understanding host protection against $M t b$.

Studies investigating adaptive response using additional immunological assays show IFN- $\gamma$ independent T-cell responses, differences in T-cell receptors, as well as the presence of antibodies in many of the studies $(4,20,21,25,29,34)$. This highlights the significance of avoiding terms such as innate or adaptive resistance until both mechanisms have been further illustrated. Similarly, terms such as early clearance or resistance to $M t b$ infection are imprecise. Both assume infection but are unable to unequivocally prove it. Crucially, the description of what was measured should be given preference rather than using terminology inferring underlying immunological or biological events (92).

As has been previously proposed, descriptions of the observed states of outcome should rather be used (92). Based on Lalvani et al.'s suggestion and by using the easily accessible TST as well as IGRA at the baseline and follow-up visits, a phenotype can be defined as 'persistently IGRA/TST negative (nonconverters), transiently IGRA/TST positive (reverters or conversion), or sustained IGRA/TST conversion (92)'. With prolonged followup and at least 2 visits, those who remain TST/IGRA negative are termed persistent nonconverters and those who remain positive would be termed persistent converters. For further definition, detailed innate and adaptive immunological assays are required (Figures 1).

\section{CONCLUSION}

Based on our review, the lack of a unifying definition of the "resister" phenotype in the literature is apparent. As described above, we found differences in how some key components were assessed and incorporated into the definition of this phenotype. Moving forward, we propose the following recommendations when trying to identify "resisters" in household contact studies or community based studies: First, the extent of exposure must be measured and considered when defining resistance. This would be ideally done using an epidemiological risk score that has been validated across different types of studies and settings such as those used by Stein et al., Mave et al. and Verrall et al. Second, both IGRA and TST must be used when evaluating an individual's response to $M t b$ and a stricter cut-off criteria should be considered for both tests. Third, the durability of the phenotype must be tested across multiple time points, ideally during at least a year of follow-up. Lastly, we propose that studies avoid terms which make assumptions about pathophysiological states which can only be inferred, such as infection. In addition, a review of both the innate and adaptive responses should be conducted before deciding on the final phenotype definition.

\section{AUTHOR CONTRIBUTIONS}

CS and MM conceived of the idea for the manuscript. JG and EK drafted the manuscript. All authors contributed to the article and approved the submitted version.

\section{FUNDING}

This work was supported by the National Institutes of Health [1R01AI124349-01]. This research was partially funded by the 
South African government through the South African Medical Research Council (SAMRC) and supported by the National Research Foundation of South Africa. The content is solely the responsibility of the authors and does not necessarily represent the official views of the SAMRC. EK is supported through funding by the SAMRC through its Division of Research Capacity Development under the Clinician Researcher Development PHD Scholarship Programme. EK is also supported by a Career Development Fellowship [TMA2018CDF2353-NeutroTB] awarded by The European and Developing Countries Clinical Trials Partnership. JG was supported by NIH training grant HL007567 and CS was supported by NIH grants R01AI124348, UO1-AI-09-001, and RO1AI147319. Funders were not involved in the writing of the manuscript or the decision to submit it for publication.

\section{REFERENCES}

1. WHO. Global tuberculosis report 2019, in: WHO. Available at: http://www. who.int/tb/publications/global_report/en/ (Accessed October 31, 2019).

2. Simmons JD, Stein CM, Seshadri C, Campo M, Alter G, Fortune S, et al. Immunological mechanisms of human resistance to persistent Mycobacterium tuberculosis infection. Nat Rev Immunol (2018) 18:575-89. doi: 10.1038/s41577-018-0025-3

3. Lu LL, Chung AW, Rosebrock TR, Ghebremichael M, Yu WH, Grace PS, et al. A Functional Role for Antibodies in Tuberculosis. Cell (2016) 167:433443.e14. doi: 10.1016/j.cell.2016.08.072

4. Lu LL, Smith MT, Yu KKQ, Luedemann C, Suscovich TJ, Grace PS, et al. IFN$\gamma$-independent immune markers of Mycobacterium tuberculosis exposure. Nat Med (2019) 25:977-87. doi: 10.1038/s41591-019-0441-3

5. McHenry ML, Williams SM, Stein CM. Genetics and evolution of tuberculosis pathogenesis: New perspectives and approaches. Infect Genet Evol (2020) 81:104204. doi: 10.1016/j.meegid.2020.104204

6. Stein CM, Zalwango S, Malone LL, Thiel B, Mupere E, Nsereko M, et al. Resistance and Susceptibility to Mycobacterium tuberculosis Infection and Disease in Tuberculosis Households in Kampala, Uganda. Am J Epidemiol (2018) 187:1477-89. doi: 10.1093/aje/kwx380

7. Badger TL, Ayrazian LF. Clinical Observations on the Pathogenesis of Tuberculosis: From a 15 Year Follow-up of 745 Nurses. Trans Am Clin Climatol Assoc (1948) 60:12-28.

8. Badger TL, Ayvazian LF. Tuberculosis in nurses; clinical observations on its pathogenesis as seen in a 15 year follow-up of 745 nurses. Am Rev Tuberc (1949) 60:305-31. doi: 10.1164/art.1949.60.3.305

9. Myers JA, Boynton RE, Diehl HS. Prevention of Tuberculosis among Students of Nursing. Am J Nurs (1947) 47:661-6. doi: 10.2307/3457892

10. Hardy MA, Schmidek HH. Epidemiology of tuberculosis aboard a ship. JAMA (1968) 203:175-9.

11. Stein CM, Hall NB, Malone LL, Mupere E. The household contact study design for genetic epidemiological studies of infectious diseases. Front Genet (2013) 4:61:61. doi: 10.3389/fgene.2013.00061

12. Stein CM, Nsereko M, Malone LL, Okware B, Kisingo H, Nalukwago S, et al. Long-term Stability of Resistance to Latent Mycobacterium tuberculosis Infection in Highly Exposed Tuberculosis Household Contacts in Kampala, Uganda. Clin Infect Dis (2019) 68:1705-12. doi: 10.1093/cid/ciy751

13. Mandalakas AM, Detjen AK, Hesseling AC, Benedetti A, Menzies D. Interferon-gamma release assays and childhood tuberculosis: systematic review and meta-analysis. Int J Tuberc Lung Dis (2011) 15:1018-32. doi: 10.5588/ijtld.10.0631

14. Ma N, Zalwango S, Malone LL, Nsereko M, Wampande EM, Thiel BA, et al. Clinical and epidemiological characteristics of individuals resistant to $\mathrm{M}$. tuberculosis infection in a longitudinal $\mathrm{TB}$ household contact study in Kampala, Uganda. BMC Infect Dis (2014) 14:352. doi: 10.1186/1471-233414-352

\section{ACKNOWLEDGMENTS}

The work herein was made possible through funding by the South African Medical Research Council through its Division of Research Capacity Development under the SAMRC Clinician Researcher MD PhD Development program. The content of any Publications from any studies during this Degree are solely the responsibility of the authors and do not necessarily represent the official views of the South African Medical Research Council. This publication is supported by NeutroTB which is part of the EDCTP2 program supported by the European Union (grant number TMA2018CDF2353-NeutroTB). The views and opinions of authors expressed herein do not necessarily state or reflect those of EDCTP. The authors would also like to thank Drs. W. Henry Boom, Thomas Hawn, and Chetan Seshadri for helpful discussion.

15. Mave V, Chandrasekaran P, Chavan A, Shivakumar SVBY, Danasekaran K, Paradkar M, et al. Infection free "resisters" among household contacts of adult pulmonary tuberculosis. PloS One (2019) 14:e0218034. doi: 10.1371/ journal.pone.0218034

16. Verrall AJ, Alisjahbana B, Apriani L, Novianty N, Nurani AC, van Laarhoven A, et al. Early Clearance of Mycobacterium tuberculosis: The INFECT Case Contact Cohort Study in Indonesia. J Infect Dis (2020) 221:1351-60. doi: 10.1093/infdis/jiz168

17. Verrall AJ, Schneider M, Alisjahbana B, Apriani L, van Laarhoven A, Koeken VACM, et al. Early Clearance of Mycobacterium tuberculosis Is Associated With Increased Innate Immune Responses. J Infect Dis (2020) 221:1342-50. doi: 10.1093/infdis/jiz147

18. Hill PC, Brookes RH, Fox A, Jackson-Sillah D, Jeffries DJ, Lugos MD, et al. Longitudinal assessment of an ELISPOT test for Mycobacterium tuberculosis infection. PloS Med (2007) 4:e192. doi: 10.1371/journal. pmed.0040192

19. Coulter F, Parrish A, Manning D, Kampmann B, Mendy J, Garand M, et al. IL-17 Production from T Helper 17, Mucosal-Associated Invariant T, and $\gamma \delta$ Cells in Tuberculosis Infection and Disease. Front Immunol (2017) 8:1252. doi: 10.3389/fimmu.2017.01252

20. Medawar L, Tukiman HM, Mbayo G, Donkor S, Owolabi O, Sutherland JS. Analysis of cellular and soluble profiles in QuantiFERON nonconverters, converters, and reverters in the Gambia. Immun Inflammation Dis (2019) 7:260-70. doi: 10.1002/iid3.269

21. Weiner J, Domaszewska T, Donkor S, Kaufmann SHE, Hill PC, Sutherland JS. Changes in transcript, metabolite and antibody reactivity during the early protective immune response in humans to Mycobacterium tuberculosis infection. Clin Infect Dis (2019) 71(1):30-40. doi: 10.1093/cid/ciz785

22. Aissa K, Madhi F, Ronsin N, Delarocque F, Lecuyer A, Decludt B, et al. Evaluation of a model for efficient screening of tuberculosis contact subjects. Am J Respir Crit Care Med (2008) 177:1041-7. doi: 10.1164/rccm.2007111756OC

23. Cobat A, Poirier C, Hoal E, Boland-Auge A, de La Rocque F, Corrard F, et al. Tuberculin skin test negativity is under tight genetic control of chromosomal region 11p14-15 in settings with different tuberculosis endemicities. J Infect Dis (2015) 211:317-21. doi: 10.1093/infdis/jiu446

24. Quistrebert J, Orlova M, Kerner G, Ton LT, Luong NT, Danh NT, et al. Genome-wide association study of resistance to Mycobacterium tuberculosis infection identifies a locus at 10q26.2 in three distinct populations. medRxiv (2020). doi: 10.1101/2020.07.14.20152801

25. Chen Z-Y, Wang L, Gu L, Qu R, Lowrie DB, Hu Z, et al. Decreased Expression of CD69 on T Cells in Tuberculosis Infection Resisters. Front Microbiol (2020) 11:1901:1901. doi: 10.3389/fmicb.2020.01901

26. Vorkas CK, Wipperman MF, Li K, Bean J, Bhattarai SK, Adamow M, et al. Mucosal-associated invariant and $\gamma \delta \mathrm{T}$ cell subsets respond to initial Mycobacterium tuberculosis infection. JCI Insight (2018) 3(19):e121899. doi: 10.1172/jci.insight.121899 
27. Cobat A, Gallant CJ, Simkin L, Black GF, Stanley K, Hughes J, et al. Two loci control tuberculin skin test reactivity in an area hyperendemic for tuberculosis. J Exp Med (2009) 206:2583-91. doi: 10.1084/jem.20090892

28. Gallant CJ, Cobat A, Simkin L, Black GF, Stanley K, Hughes J, et al. Impact of age and sex on mycobacterial immunity in an area of high tuberculosis incidence. Int J Tuberc Lung Dis (2010) 14:952-9.

29. Kroon EE, Kinnear CJ, Orlova M, Fischinger S, Shin S, Boolay S, et al. An observational study identifying highly tuberculosis-exposed, HIV-1-positive but persistently TB, tuberculin and IGRA negative persons with $\mathrm{M}$. tuberculosis specific antibodies in Cape Town, South Africa. EBioMedicine (2020) 61:103053. doi: 10.1016/j.ebiom.2020.103053

30. Mahomed H, Hawkridge T, Verver S, Geiter L, Hatherill M, Abrahams D-A, et al. Predictive factors for latent tuberculosis infection among adolescents in a high-burden area in South Africa. Int J Tuberc Lung Dis (2011) 15:331-6.

31. Nemes E, Rozot V, Geldenhuys H, Bilek N, Mabwe S, Abrahams D, et al. Optimization and Interpretation of Serial QuantiFERON Testing to Measure Acquisition of Mycobacterium tuberculosis Infection. Am J Respir Crit Care Med (2017) 196:638-48. doi: 10.1164/rccm.201704-0817OC

32. Andrews JR, Nemes E, Tameris M, Landry BS, Mahomed H, McClain JB, et al. Serial QuantiFERON testing and tuberculosis disease risk among young children: an observational cohort study. Lancet Respir Med (2017) 5:282-90. doi: 10.1016/S2213-2600(17)30060-7

33. Simmons J, Van PT, Stein CM, Chihota V, Ntshiqa T, Maenetje P, et al. Monocyte fatty acid transcriptional programs and AMPK polymorphisms associate with resistance to TST/IGRA conversion. in (Keystone Virtual 2020 Abstract). Available at: https://virtual.keystonesymposia.org/ks/live/551/page/3981/7236.

34. Li H, Wang X-X, Wang B, Fu L, Liu G, Lu Y, et al. Latently and uninfected healthcare workers exposed to $\mathrm{TB}$ make protective antibodies against Mycobacterium tuberculosis. Proc Natl Acad Sci USA (2017) 114:5023-8. doi: 10.1073/pnas.1611776114

35. Verrall AJ, Netea MG, Alisjahbana B, Hill PC, van Crevel R. Early clearance of Mycobacterium tuberculosis: a new frontier in prevention. Immunology (2014) 141:506-13. doi: 10.1111/imm.12223

36. Ugarte-Gil C, Alisjahbana B, Ronacher K, Riza AL, Koesoemadinata RC, Malherbe ST, et al. Diabetes Mellitus Among Pulmonary Tuberculosis Patients From 4 Tuberculosis-endemic Countries: The TANDEM Study. Clin Infect Dis (2020) 70:780-8. doi: 10.1093/cid/ciz284

37. Jabot-Hanin F, Cobat A, Feinberg J, Grange G, Remus N, Poirier C, et al. Major Loci on Chromosomes 8q and 3q Control Interferon $\gamma$ Production Triggered by Bacillus Calmette-Guerin and 6-kDa Early Secretory Antigen Target, Respectively, in Various Populations. J Infect Dis (2015) 213(7):11739. doi: 10.1093/infdis/jiv757

38. Tadokera R, Bekker L-G, Kreiswirth BN, Mathema B, Middelkoop K. TB transmission is associated with prolonged stay in a low socio-economic, high burdened TB and HIV community in Cape Town, South Africa. BMC Infect Dis (2020) 20:1-9. doi: 10.1186/s12879-020-4828-Z

39. Verver S, Warren RM, Munch Z, Richardson M, van der Spuy GD, Borgdorff MW, et al. Proportion of tuberculosis transmission that takes place in households in a high-incidence area. Lancet (2004) 363:212-4. doi: 10.1016/ S0140-6736(03)15332-9

40. Andrews JR, Morrow C, Wood R. Modeling the role of public transportation in sustaining tuberculosis transmission in South Africa. Am J Epidemiol (2013) 177:556-61. doi: 10.1093/aje/kws331

41. Classen C, Warren R, Richardson M, Hauman J, Gie R, Ellis J, et al. Impact of social interactions in the community on the transmission of tuberculosis in a high incidence area. Thorax (1999) 54:136-40. doi: 10.1136/ thx.54.2.136

42. Escombe AR, Huaroto L, Ticona E, Burgos M, Sanchez I, Carrasco L, et al. Tuberculosis transmission risk and infection control in a hospital emergency department in Lima, Peru. Int J Tuberc Lung Dis (2010) 14:1120-6.

43. Uys PW, van Helden PD, Hargrove JW. Tuberculosis reinfection rate as a proportion of total infection rate correlates with the logarithm of the incidence rate: a mathematical model. J R Soc Interface (2009) 6:11-5. doi: 10.1098/ rsif.2008.0184

44. Van Rie A, Warren R, Richardson M, Victor TC, Gie RP, Enarson DA, et al. Exogenous reinfection as a cause of recurrent tuberculosis after curative treatment. NEnglJMed (1999) 341:1174-9. doi: 10.1056/NEJM199910143411602
45. Wood R, Liang H, Wu H, Middelkoop K, Oni T, Rangaka MX, et al. Changing prevalence of TB infection with increasing age in high TB burden townships in South Africa. Int J Tuberc Lung Dis (2010) 14:406-12.

46. Yates TA, Khan PY, Knight GM, Taylor JG, McHugh TD, Lipman M, et al. The transmission of Mycobacterium tuberculosis in high burden settings. Lancet Infect Dis (2016) 16:227-38. doi: 10.1016/S1473-3099(15)00499-5

47. Crampin AC, Mwaungulu JN, Mwaungulu FD, Mwafulirwa DT, Munthali K, Floyd S, et al. Recurrent TB: relapse or reinfection? The effect of HIV in a general population cohort in Malawi. AIDS (2010) 24:417-26. doi: 10.1097/ QAD.0b013e32832f51cf

48. Houben RMGJ, Crampin AC, Ndhlovu R, Sonnenberg P, Godfrey-Faussett P, Haas WH, et al. Human immunodeficiency virus associated tuberculosis more often due to recent infection than reactivation of latent infection [Review article]. Int J Tuberc Lung Dis (2011) 15:24-31.

49. Sonnenberg P, Murray J, Glynn JR, Shearer S, Kambashi B, Godfrey-Faussett P. HIV-1 and recurrence, relapse, and reinfection of tuberculosis after cure: a cohort study in South African mineworkers. Lancet (2001) 358:1687-93. doi: $10.1016 / \mathrm{S} 0140-6736(01) 06712-5$

50. Andrews JR, Morrow C, Walensky RP, Wood R. Integrating social contact and environmental data in evaluating tuberculosis transmission in a South African township. J Infect Dis (2014) 210:597-603. doi: 10.1093/infdis/jiu138

51. Marais BJ, Hesseling AC, Schaaf HS, Gie RP, van Helden PD, Warren RM. Mycobacterium tuberculosis Transmission Is Not Related to Household Genotype in a Setting of High Endemicity. J Clin Microbiol (2009) 47:133843. doi: $10.1128 /$ JCM.02490-08

52. Marais BJ, Victor TC, Hesseling AC, Barnard M, Jordaan A, Brittle W, et al. Beijing and Haarlem Genotypes Are Overrepresented among Children with Drug-Resistant Tuberculosis in the Western Cape Province of South Africa. J Clin Microbiol (2006) 44:3539-43. doi: 10.1128/JCM.01291-06

53. Zelner JL, Murray MB, Becerra MC, Galea J, Lecca L, Calderon R, et al. Agespecific risks of tuberculosis infection from household and community exposures and opportunities for interventions in a high-burden setting. Am J Epidemiol (2014) 180(8):853-61. doi: 10.1093/aje/kwu192

54. Middelkoop K, Mathema B, Myer L, Shashkina E, Whitelaw A, Kaplan G, et al. Transmission of Tuberculosis in a South African Community With a High Prevalence of HIV Infection. J Infect Dis (2015) 211:53-61. doi: 10.1093/ infdis/jiu 403

55. Middelkoop K, Bekker L-G, Myer L, Dawson R, Wood R. Rates of tuberculosis transmission to children and adolescents in a community with a high prevalence of HIV infection among adults. Clin Infect Dis (2008) 47(3):34955. doi: $10.1086 / 589750$

56. Andrews JR, Hatherill M, Mahomed H, Hanekom WA, Campo M, Hawn TR, et al. The Dynamics of QuantiFERON-TB Gold In-Tube Conversion and Reversion in a Cohort of South African Adolescents. Am J Respir Crit Care Med (2015) 191:584-91. doi: 10.1164/rccm.201409-1704OC

57. Mahomed H, Hawkridge T, Verver S, Abrahams D, Geiter L, Hatherill M, et al. The tuberculin skin test versus QuantiFERON TB Gold ${ }^{\circledR}$ in predicting tuberculosis disease in an adolescent cohort study in South Africa. PloS One (2011) 6:e17984. doi: 10.1371/journal.pone.0017984

58. Mahomed H, Ehrlich R, Hawkridge T, Hatherill M, Geiter L, Kafaar F, et al. Screening for TB in high school adolescents in a high burden setting in South Africa. Tuberc (Edinb) (2013) 93:357-62. doi: 10.1016/j.tube.2013.02.007

59. Hanifa Y, Grant AD, Lewis J, Corbett EL, Fielding K, Churchyard G. Prevalence of latent tuberculosis infection among gold miners in South Africa. Int J Tuberc Lung Dis (2009) 13:39-46.

60. Vynnycky E, Sumner T, Fielding KL, Lewis JJ, Cox AP, Hayes RJ, et al. Tuberculosis Control in South African Gold Mines: Mathematical Modeling of a Trial of Community-Wide Isoniazid Preventive Therapy. Am J Epidemiol (2015) 181:619-32. doi: 10.1093/aje/kwu320

61. Wallis RS. Mathematical Models of Tuberculosis Reactivation and Relapse. Front Microbiol (2016) 7:669. doi: 10.3389/fmicb.2016.00669

62. Morrison J, Pai M, Hopewell PC. Tuberculosis and latent tuberculosis infection in close contacts of people with pulmonary tuberculosis in lowincome and middle-income countries: a systematic review and meta-analysis. Lancet Infect Dis (2008) 8:359-68. doi: 10.1016/S1473-3099(08)70071-9

63. Behr MA, Edelstein PH, Ramakrishnan L. Is Mycobacterium tuberculosis infection life long? BMJ (2019) 367:15770. doi: 10.1136/bmj.15770 
64. Houk VN, Kent DC, Sorensen K, Baker JH. The eradication of tuberculosis infection by isoniazid chemoprophylaxis. Arch Environ Health (1968) 16:4650. doi: 10.1080/00039896.1968.10665013

65. Menzies D. Interpretation of repeated tuberculin tests. Boosting, conversion, and reversion. Am J Respir Crit Care Med (1999) 159:15-21. doi: 10.1164/ ajrccm.159.1.9801120

66. Sepulveda RL, Araya D, Ferrer X, Sorensen RU. Repeated tuberculin testing in patients with active pulmonary tuberculosis. Chest (1993) 103:359-63. doi: 10.1378/chest.103.2.359

67. Rangaka MX, Wilkinson KA, Glynn JR, Ling D, Menzies D, MwansaKambafwile J, et al. Predictive value of interferon- $\gamma$ release assays for incident active tuberculosis: a systematic review and meta-analysis. Lancet Infect Dis (2012) 12:45-55. doi: 10.1016/S1473-3099(11)70210-9

68. Package Inserts QFT-Plus - QuantiFERON. Available at: https://www. quantiferon.com/products/quantiferon-tb-gold-plus-qft-plus/packageinserts/ (Accessed January 29, 2020).

69. Shafeque A, Bigio J, Hogan CA, Pai M, Banaei N. Fourth generation QuantiFERON-TB Gold-Plus: What is the evidence? J Clin Microbiol (2020) 58(9):e01950-19. doi: 10.1128/JCM.01950-19

70. Barcellini L, Borroni E, Brown J, Brunetti E, Campisi D, Castellotti PF, et al. First evaluation of QuantiFERON-TB Gold Plus performance in contact screening. Eur Respir J (2016) 48:1411-9. doi: 10.1183/ 13993003.00510-2016

71. Takasaki J, Manabe T, Morino E, Muto Y, Hashimoto M, Iikura M, et al. Sensitivity and specificity of QuantiFERON-TB Gold Plus compared with QuantiFERON-TB Gold In-Tube and T-SPOT.TB on active tuberculosis in Japan. J Infect Chemother (2018) 24:188-92. doi: 10.1016/ j.jiac.2017.10.009

72. Venkatappa TK, Punnoose R, Katz DJ, Higgins MP, Banaei N, Graviss EA, et al. Comparing QuantiFERON-TB Gold Plus with Other Tests To Diagnose Mycobacterium tuberculosis Infection. J Clin Microbiol (2019) 57:e00985-19. doi: 10.1128/JCM.00985-19

73. Zhang H, Xin H, Wang D, Pan S, Liu Z, Cao X, et al. Serial testing of Mycobacterium tuberculosis infection in Chinese village doctors by QuantiFERON-TB Gold Plus, QuantiFERON-TB Gold in-Tube and TSPOT.TB. J Infect (2019) 78:305-10. doi: 10.1016/j.jinf.2019.01.008

74. Hoffmann H, Avsar K, Göres R, Mavi S-C, Hofmann-Thiel S. Equal sensitivity of the new generation QuantiFERON-TB Gold plus in direct comparison with the previous test version QuantiFERON-TB Gold IT. Clin Microbiol Infect (2016) 22:701-3. doi: 10.1016/j.cmi.2016.05.006

75. Petruccioli E, Chiacchio T, Pepponi I, Vanini V, Urso R, Cuzzi G, et al. First characterization of the CD4 and CD8 T-cell responses to QuantiFERON-TB Plus. J Infect (2016) 73:588-97. doi: 10.1016/j.jinf.2016.09.008

76. Siegel SAR, Cavanaugh M, Ku JH, Kawamura LM, Winthrop KL. Specificity of QuantiFERON-TB Plus, a New-Generation Interferon Gamma Release Assay. J Clin Microbiol (2018) 56(12):e00629-18. doi: 10.1128/JCM.00629-18

77. Wang L, Tian X-D, Yu Y, Chen W. Evaluation of the performance of two tuberculosis interferon gamma release assays (IGRA-ELISA and T-SPOT.TB) for diagnosing Mycobacterium tuberculosis infection. Clin Chim Acta (2018) 479:74-8. doi: 10.1016/j.cca.2018.01.014

78. Telisinghe L, Amofa-Sekyi M, Maluzi K, Kaluba-Milimo D, Cheeba-Lengwe $\mathrm{M}$, Chiwele K, et al. The sensitivity of the QuantiFERON ${ }^{\circledR}-$ TB Gold Plus assay in Zambian adults with active tuberculosis. Int J Tuberc Lung Dis (2017) 21:690-6. doi: 10.5588/ijtld.16.0764

79. König Walles J, Tesfaye F, Jansson M, Tolera Balcha T, Winqvist N, Kefeni M, et al. Performance of QuantiFERON-TB Gold Plus for detection of latent tuberculosis infection in pregnant women living in a tuberculosis- and HIVendemic setting. PloS One (2018) 13:e0193589. doi: 10.1371/journal.pone.0193589
80. van Zyl-Smit RN, Zwerling A, Dheda K, Pai M. Within-Subject Variability of Interferon-g Assay Results for Tuberculosis and Boosting Effect of Tuberculin Skin Testing: A Systematic Review. PloS One (2009) 4:e8517. doi: 10.1371/ journal.pone.0008517

81. Lindsay RP, Shin SS, Garfein RS, Rusch MLA, Novotny TE. The Association between active and passive smoking and latent tuberculosis infection in adults and children in the united states: results from NHANES. PloS One (2014) 9: e93137. doi: 10.1371/journal.pone.0093137

82. Lee M-R, Huang Y-P, Kuo Y-T, Luo C-H, Shih Y-J, Shu C-C, et al. Diabetes Mellitus and Latent Tuberculosis Infection: A Systematic Review and Metaanalysis. Clin Infect Dis (2017) 64:719-27. doi: 10.1093/cid/ciw836

83. Lin H-H, Wu C-Y, Wang C-H, Fu H, Lönnroth K, Chang Y-C, et al. Association of Obesity, Diabetes, and Risk of Tuberculosis: Two Population-Based Cohorts. Clin Infect Dis (2018) 66:699-705. doi: 10.1093/ cid/cix852

84. Lin C-H, Kuo S-C, Hsieh M-C, Ho S-Y, Su I-J, Lin S-H, et al. Effect of diabetes mellitus on risk of latent $\mathrm{TB}$ infection in a high $\mathrm{TB}$ incidence area: a community-based study in Taiwan. BMJ Open (2019) 9:e029948. doi: 10.1136/bmjopen-2019-029948

85. Igo RP, Hall NB, Malone LL, Hall JB, Truitt B, Qiu F, et al. Fine-mapping Analysis of a Chromosome 2 Region Linked to Resistance to Mycobacterium tuberculosis Infection in Uganda Reveals Potential Regulatory Variants. Genes Immun (2019) 20:473-83. doi: 10.1038/s41435-018-0040-1

86. Cubilla-Batista I, Ruiz N, Sambrano D, Castillo J, de Quinzada MO, Gasteluiturri B, et al. Overweight, Obesity, and Older Age Favor Latent Tuberculosis Infection among Household Contacts in Low TuberculosisIncidence Settings within Panama. Am J Trop Med Hyg (2019) 100:1141-4. doi: 10.4269/ajtmh.18-0927

87. Ewer K, Millington KA, Deeks JJ, Alvarez L, Bryant G, Lalvani A. Dynamic antigen-specific $\mathrm{T}$-cell responses after point-source exposure to Mycobacterium tuberculosis. Am J Respir Crit Care Med (2006) 174:831-9. doi: $10.1164 / \mathrm{rccm} .200511-1783$ OC

88. Wiens KE, Woyczynski LP, Ledesma JR, Ross JM, Zenteno-Cuevas R, Goodridge A, et al. Global variation in bacterial strains that cause tuberculosis disease: a systematic review and meta-analysis. BMC Med (2018) 16:196. doi: 10.1186/s12916-018-1180-x

89. Verrall AJ. Innate Factors in Early Clearance of Mycobacterium tuberculosis (2018). Available at: https://ourarchive.otago.ac.nz/handle/10523/7999 (Accessed December 10, 2020).

90. Heimbeck J. Incidence of tuberculosis in young adult women, with special reference to employment. Br J Tuberc (1938) 32:154-66. doi: 10.1016/S03660850(38)80144-7

91. Israel HL, Hetherington HW. Ord JG. A study of tuberculosis among students of nursing. JAMA (1941) 117:839-44. doi: 10.1001/jama.1941.02820360021007

92. Lalvani A, Seshadri C. Understanding How BCG Vaccine Protects Against Mycobacterium tuberculosis Infection: Lessons From Household Contact Studies. J Infect Dis (2020) 221:1229-31. doi: 10.1093/infdis/jiz261

Conflict of Interest: The authors declare that the research was conducted in the absence of any commercial or financial relationships that could be construed as a potential conflict of interest.

Copyright (c) 2021 Gutierrez, Kroon, Möller and Stein. This is an open-access article distributed under the terms of the Creative Commons Attribution License (CC BY). The use, distribution or reproduction in other forums is permitted, provided the original author(s) and the copyright owner(s) are credited and that the original publication in this journal is cited, in accordance with accepted academic practice. No use, distribution or reproduction is permitted which does not comply with these terms. 